\title{
Tribocorrosion behavior and ions release of CoCrMo alloy coated with a TiAlVCN/CNx multilayer in simulated body fluid plus bovine serum albumin
}

\author{
B. Alemon, M. Flores, W. Ramirez, J. C. Huegel and Esteban Broitman
}

\section{Linköping University Post Print}

\section{Tweet}

N.B.: When citing this work, cite the original article.

Original Publication:

B. Alemon, M. Flores, W. Ramirez, J. C. Huegel and Esteban Broitman, Tribocorrosion behavior and ions release of CoCrMo alloy coated with a TiAlVCN/CNx multilayer in simulated body fluid plus bovine serum albumin, 2015, Tribology International, (81), 159-168. http://dx.doi.org/10.1016/j.triboint.2014.08.011

Copyright: Elsevier http://www.elsevier.com/

Postprint available at: Linköping University Electronic Press http://urn.kb.se/resolve?urn=urn:nbn:se:liu:diva-113043 
Tribocorrosion behavior and ions release of CoCrMo alloy coated with a TiAIVCN/CNx multilayer in simulated body fluid plus bovine serum albumin

\author{
B. Alemón ${ }^{1,2}$, M.Flores $^{1}$, W. Ramírez ${ }^{1}$, J.C. Huegel2 ${ }^{2}$ E.Broitman ${ }^{3}$
}

1 Departamento de ingeniería de proyectos. CUCEI, Universidad de Guadalajara, J. Guadalupe Zuno 48, Los Belenes, Zapopan Jal., 45101, México.

2 Tecnológico de Monterrey, Av. General Ramón Corona 2514, Col. Nuevo Mexico, Zapopan, Jalisco. 45201, México.

3 Thin Films Physics Division, IFM, Linköping, University, SE-58183 Linköping, Sweden.

Corresponding author. Tel.: +523314174688; Fax: +523336693061

E-mail address: balemon@itesm.mx (B. Alemón)

\begin{abstract}
While the CoCrMo biomaterial is currently employed in artificial joints, there are medical concerns regarding its metal ion release and material loss caused by tribocorrosion. In this work, a TiAIVCN/CN $\mathrm{C}_{\mathrm{x}}$ multilayer coating has been employed to improve the tribocorrosion-resistance of the CoCrMo substrate. During the tribocorrosion test, with the sample immersed in a simulated body fluid containing bovine serum albumin, open-circuit potential measurements showed more noble potential as well as a reduction of both the friction coefficient and wear-rate during the sliding phase. Inductive coupled plasma results demonstrate that the multilayer coating effectively blocked the emigration of metallic ions.
\end{abstract}

Key words: Tribocorrosion, CoCrMo, TiAIVCN/CNx multilayer, simulated body fluid, bovine serum albumin.

\title{
1. Introduction
}

CoCrMo wrought grade implant alloys are widely employed in the manufacture of prostheses for hip and knee joints due to their biocompatibility and their superior mechanical properties such as: high elastic modulus, high tensile strength, high wear resistance and high corrosion resistance. The main drawbacks and medical 
concerns regarding the use of such alloys include both the decreased biocompatibility due to the release of metal ions in the body [1-4] and the material loss caused by tribocorrosion (combined effect of wear and corrosion) [5].

Most of the time, joint prostheses perform under simultaneous loading, relative movement, wear and corrosive conditions. Tribocorrosion, defined as the conjoint action of any mechanical wear under load and corrosive attack of the material surface [6], has been shown to shorten the life of prostheses. Moreover, corrosion during reciprocating movement is accelerated by the synergistic effect of the wear [7]. This phenomenon is highly relevant to the field of biomedical joint implants in general, and specifically to hip and knee joints [7, 8]. The damage is restricted mostly to the local movement site, while the generated debris act as abrasive particles. The presence of body fluids represents an additional environmental cause of corrosion at the joint prostheses interface [9]. The natural physiological environment contains not only inorganic species but also organic molecules such as serum proteins. Bovine serum albumin (BSA) is of particular interest when studying the biocompatibility of metal implants and is considered an adequate model protein for human serum albumin (HSA). Valero et al., reported that the corrosion rate of CoCrMo is very sensitive to the amount of BSA and thereby it influences the mechanics and kinetics of the corrosion reaction on the material surface [10]. Furthermore, several electrochemical studies have shown that the constituents of bovine serum have an influence on the corrosion behavior of CoCrMo, for example it has shown that the albumin acts as a cathodic inhibitor and it accelerates the anodic reaction in solution [9-12]. Thus adding BSA to the simulated body fluid (SBF) implies an adequate experimental medium for the corrosion and tribocorrosion test of the present work.

The application of coatings may improve the corrosion and tribocorrosion properties of CoCrMo alloys. DLC (diamond like carbon) and $\mathrm{CN}_{x}$ carbon nitride monolayer coatings are currently being studied as candidates for the coating of CoCrMo biomedical alloys because of their superior mechanical properties such as high hardness, and high wear resistance coupled with excellent biocompatibility [13]. But DLC coatings have shown a sudden failure of layers whose interfaces are too weak with respect to the stress-corrosion cracking mechanism [14]. Amorphous carbon (a-C) films have shown a poor adhesion to the substrates, which is caused mainly by high residual stresses in film and high diffusion of carbon into the substrate (i.e. steel) [15]. But Broitman et al. reported that $\mathrm{CN}_{\mathrm{x}}$ films deposited by reactive 
magnetron sputtering on metallic biomaterials exhibit good tribological properties and improved adhesion on metallic substrates [16-18]. Moreover the low coefficient of friction (COF) of $\mathrm{CN}_{x}$ films has the potential to cause lower wear against polymeric materials such as ultra-high molecular weight polyethylene (UHMWPE) in human serum conditions [19]. UHMWPE is one of the biocompatible materials most employed for the counterpart surface of both hip and knee joints. Recent research has shown that monolayer coatings of Ti incorporated amorphous $\mathrm{CN}_{\mathrm{x}}\left(\mathrm{a}-\mathrm{CN}_{\mathrm{x}}\right)$ film present a successful improvements in corrosion resistance and biocompatibility [20]. Since the long-term durability of the prosthetic joint materials rely on the successful control of both the corrosion that produces ions release and the tribocorrosion resistance that produces ions release and oxide or plastic debris, Physical Vapor Deposition (PVD) multilayer coatings offer a multifunctional protection alternative and good adherence to metallic substrates in comparison to the monolayer coating [15, 21-26]. The multilayer combine the properties of different materials in a single protective layer. The introduction of a number of interfaces parallel to the substrate surface can act to deflect cracks or provide barriers to dislocation motion, increasing the toughness and hardness of the coating $[27,28]$. For example crystalline transition metal nitride/a- $\mathrm{CN}_{x}$ multilayer such as $\mathrm{TiN} / \mathrm{CN}_{\mathrm{x}}, \mathrm{ZrN} / \mathrm{CN}_{\mathrm{x}}, \mathrm{CrN} / \mathrm{CN}_{\mathrm{x}}$ and $\mathrm{NbN} / \mathrm{CN}_{\mathrm{x}}$ exhibit good tribological behavior and improved adhesion on the metal substrates by means of stress relaxation [29]. The corrosion resistance of CoCrMo coated with TiN/TiAIN multilayers is better than the CoCrMo alloy coated with TiN or TiAIN single coatings [23]. In a previous work we reported that a similar multilayer of TiAICN/CNx multilayer improved the mechanical properties and the corrosion resistance of CoCrMo [30]. Therefore, in the current work we hypothesize that multilayers of TiAIVCN/CN $/ N_{x}$ may combine the excellent mechanical tribological characteristics of the ceramic crystalline layers of (TiAIVC)N with the low friction and improved adhesion of the amorphous $\mathrm{CN}_{\mathrm{x}}$ layers [19,31]. Moreover the amorphous layer can interrupt the defects, grain boundaries and pinholes, reducing the permeability of ceramic-crystalline/amorphous multilayer.

There are few studies regarding the tribocorrosion behavior of the CoCrMo alloy in SBF+BSA [32,33]. There are also only a few publications regarding the tribocorrosion behavior of multilayer coatings $[25,34,35]$ and fewer studies yet of the tribological behavior of TiAICN/TiAIN and nanocomposite (nc) TiAIV(N,C)/amorphous C multilayer [36]. 
The aim of this work then, is to improve the corrosion and tribocorrosion behavior of the substrate CoCrMo in the presence of SBF plus BSA by applying a TiAIVCN/CN $\mathrm{N}_{\mathrm{x}}$ multilayer coating deposited by magnetron sputtering. We evaluated the nanomechanical properties including hardness $(H)$, reduced Young's Modulus $\left(E_{r}\right)$ and elastic recovery $(\% R)$. The primary results of this work compare the corrosion resistance and ions release rate while submerging both the substrate and coated samples in a bovine serum albumin charged SBF. We also compare the tribocorrosion behavior of all samples by monitoring values of the open circuit potential (OCP) and COF during the tribocorrosion test.

\section{Materials and experimental procedure}

The substrate employed for the experiments was the LC CoCrMo alloy (ASTM F1537, ASTM F799) standard forging alloy for surgical implants. It contains: C (0.04\%), Mn (0.81\%), Si (0.16\%), Cr (27.58\%), Ni (0.14\%), Mo (5.48\%), Co $(64.99 \%), \mathrm{N}(0.16 \%)$. Discs of $31.75 \mathrm{~mm}$ in diameter and $6 \mathrm{~mm}$ thick were ground flat with sandpaper $(240,400,600$, and 1200) and subsequently polished with a diamond paste of $1 \mu \mathrm{m}$. Before the deposition of the multilayer coating, the samples were ultrasonically cleaned for fifteen minutes in acetone and then in isopropyl alcohol.

Figure1 shows a schematic representation of the multilayer structure used in the present research. It has: a metal layer of TiAIV to promote adhesion of the multilayer, 9 layers of $\mathrm{CN}_{\mathrm{x}}$ alternating with 9 layers of TiAIVCN and finally a relatively thick $\mathrm{CN}_{\mathrm{x}}$ layer deposited on the top of the multilayer to reduce the coating COF [16]. Based on prior work by our group, the total thickness of the multilayer has been chosen to be from 3.0 to $3.5 \mu \mathrm{m}[30]$. 


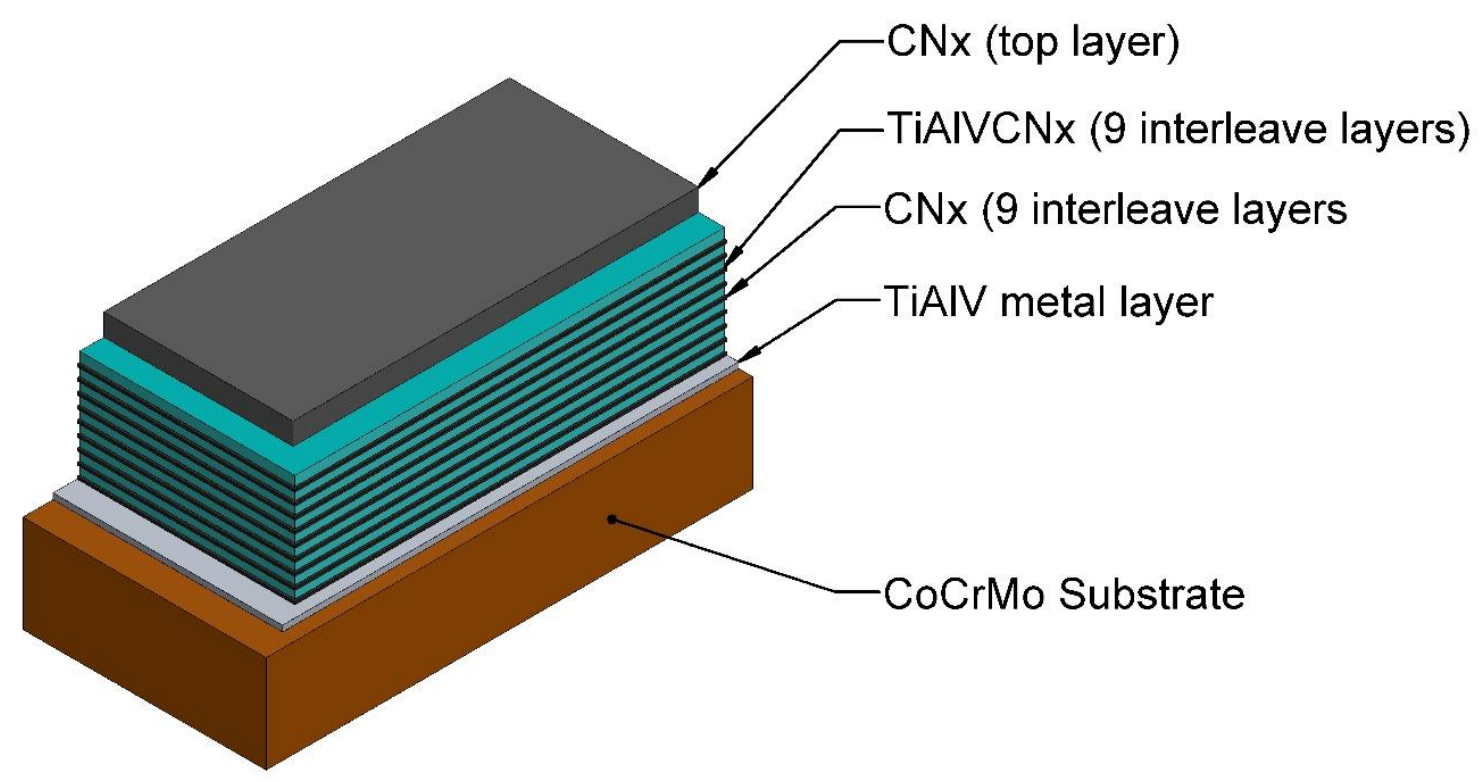

Figure 1. Schematic representation of the multilayer coating TiAIVCN/CN $\mathrm{x}$ deposited on CoCrMo alloy. The figure shows the metal layer of TiAIV, $9 \mathrm{CN}_{\mathrm{x}}$ layers interleaved with layers 9TiAIVCN layers, and the top layer of $\mathrm{CN}_{\mathrm{x}}$.

Deposition of the TiAIVCN/CN $\mathrm{N}_{\mathrm{x}}$ multilayer on the CoCrMo substrate was carried out in a DC and RF magnetron sputtering system. The substrates rotated in the process at a distance of $60 \mathrm{~mm}$ from the targets. High purity graphite $(99.99 \%)$ and a commercial alloy Ti6Al4V $(90 \% \mathrm{Ti}, 6 \% \mathrm{Al}, 4 \% \mathrm{~V})$ were used as targets. The parameters of the magnetron sputtering process were similar to those reported by Broitman et al. for $\mathrm{CN}_{\mathrm{x}}$ and by Flores et al. for metal ceramic $[16,37]$. The initial vacuum pressure was $3.9 \times 10^{-4} \mathrm{~Pa}\left(3 \times 10^{-6} \mathrm{Torr}\right)$.

All substrates were preheated to $125^{\circ} \mathrm{C}$ for $30 \mathrm{~min}$ to reach a uniform temperature. After the preheat time, the substrates were sputter-cleaned using radio frequency (RF) applied to the substrates with the argon pressure set to $1.3 \mathrm{~Pa}$ (10mTorr) with a power of 40 watts for 20 minutes. Prior to the deposition of the multilayer on the CoCrMo alloy, a metal layer was deposited by sputtering of the Ti6Al4V target in an argon discharge at a pressure of $1.3 \mathrm{~Pa}$ (10mTorr) and a DC constant current of $0.6 \mathrm{~A}$, thereby promoting the adhesion of the subsequent multilayer to the substrate. Multilayer TiAIVCN/CN $\mathrm{N}_{x}$, was grown at a temperature of 
$\sim 125^{\circ} \mathrm{C}$. The TiAIVCN layers were obtained by a codeposition of TiAIV and graphite targets. The TiAIV was deposited employing a DC source with a constant current of 0.6 A and graphite with the RF power source at a power density of 10 wattscm ${ }^{-2}$ and at an argon/nitrogen pressure of $\sim 1.7 \mathrm{~Pa}$ (13mTorr) and a substrate bias voltage of $-40 \mathrm{~V}$. Both the $\mathrm{CN}_{\mathrm{x}}$ interlayers and top layer were generated by deposition of graphite using RF sputtering at a power density of $10 \mathrm{Watts} / \mathrm{cm}^{2}$ an $\mathrm{Ar} / \mathrm{N}_{2}$ pressure of 1.6 $\mathrm{Pa}$ (12mTorr). The proportion of $\mathrm{Ar} / \mathrm{N}_{2}$ was varied during the deposition process: $60 / 40$ for TiAICN and 43/57 for CN. Each layer was deposited without turning off the plasma in order to obtain a gradual change between the layers.

\subsection{Morphological and structural characterization}

Multilayer coating morphology, thickness and surface analysis is obtained by means of Field Emission Scanning Electron Microscopy (FE-SEM) with a high resolution Tescan Mira 3MLU. The crystal structure of the CoCrMo wrought alloy and multilayer coating was analyzed using a Siemens D500 X-ray diffractometer with $\mathrm{Cu}$ $\mathrm{Ka}$ radiation. A conventional $\theta / 2 \theta$ Bragg-Brentano symmetric geometry was used, from $20^{\circ}$ to $80^{\circ}$ with a step size of $0.03^{\circ}$ and step-time of $1 \mathrm{~s}$. The $\mathrm{x}$-ray source was operated at $20 \mathrm{~mA}$ and $30 \mathrm{kV}$.

\subsection{Chemical composition}

Depth profiling of the chemical composition of the coating was carried out using X-ray photoelectron spectroscopy (XPS) with an axis ultra DLD from Kratos Analytical. The test was performed using monochromatic $\mathrm{Al}\left(\mathrm{K}_{\mathrm{a}}\right) \mathrm{X}$-ray radiation ( $\mathrm{h} v=$ $1486.6 \mathrm{eV}$ ). XPS core level spectra of the Al2p, C1s, N1s, Ti2p, V2p, and O1s regions were recorded first on as-received samples and after a sputter clean for 120 s with $500 \mathrm{eVAr}^{+}$ion beam raster scan over the area of $3 \times 3 \mathrm{~mm}^{2}$ at an incidence angle of $20^{\circ}$ with respect to the sample surface. Subsequent to the sample surface XPS measurements, depth profiles were acquired on the multilayer coating. Alternating sequences of corresponding core level spectra measurement and sputter etching with a $4 \mathrm{keV} \mathrm{Ar}^{+}$ion beam obtained the sputter profiles. At the beginning,

gentle sputter clean conditions were chosen, thereby preserving the bonding structure as much as possible. In this context, it should be mentioned that the sputter clean at $4 \mathrm{keV}$ may induce changes in the multi-layers in terms of both a decreased 
resolution of the main components in the core level spectra (onset of structural damage) and also an in-depth intermixing of carbon.

\subsection{Nanomechanical properties}

The nanomechanical properties of the TiAIVCN/CN $\mathrm{x}$ and substrate were evaluated by nanoindentation experiments in a TI 950 Triboindenter $^{\mathrm{TM}}$ (Hysitron). Hardness $(H)$ and reduced modulus $\left(E_{r}\right)$ measured using a Berkovich diamond indenter were calculated according to the method proposed by Oliver and Pharr [38]. In order to avoid the combined coating plus substrate effect, penetration displacement was set to slightly less than $10 \%$ of the total coating thickness. In all depth-sensing tests a total of 10 indents were averaged to determine the mean and standard deviations of $\mathrm{H}$ and $\mathrm{E}_{\mathrm{r}}$. The displacements were continuously recorded during the indentations. The penetration displacement of the indenter at maximum load $\left(h_{\max }\right)$ and the final displacement $\left(h_{f}\right)$, recorded in the unloading curve, were used to determine the percentage of elastic recovery $\% R$ according to the equation $1[16]$.

$$
\% R=\frac{h_{\max }-h_{f}}{h_{\max }}(100)
$$

\section{4 lons release comparison test}

The ion release test was performed while the samples were immersed in a solution prepared with SBF and $4 \mathrm{gL}^{-1}$ bovine serum albumin (BSA), reference (9048-46-8) from Sigma-Aldrich® (2013). One liter of SBF was prepared using deionized water and the following reagents: $\mathrm{NaCl}(8.035 \mathrm{~g}), \mathrm{NaHCO}_{3}(0.355 \mathrm{~g}), \mathrm{KCl}$ $(0.225 \mathrm{~g}), \mathrm{K}_{2} \mathrm{HPO}_{4}(0.285 \mathrm{~g}) \mathrm{MgCl}_{2} 6 \mathrm{H}_{2} \mathrm{O}(0.31 \mathrm{~g}), 1.0 \mathrm{M} \mathrm{HCl}(39 \mathrm{ml}), \mathrm{CaCl}_{2} 2 \mathrm{H}_{2} \mathrm{O}$ $(0.328 \mathrm{~g}), \mathrm{Na}_{2} \mathrm{SO}_{4}(0.072 \mathrm{~g})$. The solution was buffered adding Tris $\left(\mathrm{HOCH}_{2}\right)_{3} \mathrm{CNCH}_{2}$ $(6.118 \mathrm{~g})$ and $1.0 \mathrm{M} \mathrm{HCl}(0-5 \mathrm{ml})$ until the $\mathrm{pH}$ was 7.40 exactly at $36.5^{\circ} \mathrm{C}$ according to the method described by Tadashi Kokubo et al. The SBF prepared for the experiments is similar in the ions concentration to the human blood plasma [39]. The BSA was chosen because human and bovine albumins are similar and comprises $55-62 \%$ of the protein present $[40,41]$.

For the ion release comparison experiments the CoCrMo substrate and TiAIVCN/CN $\mathrm{N}_{\mathrm{x}}$ multilayer coated samples were cleaned with alcohol. $\mathrm{A} 1 \mathrm{~cm}^{2}$ area was delimited by double-painting with enamel, and then placed in $200 \mathrm{ml}$ of SBF+BSA 
into different beakers, in a water bath at $36.5 \pm 1.5^{\circ} \mathrm{C}$. During 7 days, $10 \mathrm{ml}$ of SBF plus BSA solution was extracted without stirring the solution and according to the following sequence: the first $10 \mathrm{ml}$ was extracted at the first hour, then at 3, 6 and 24 hours of immersion time. After the first 24 hours, $10 \mathrm{ml}$ were extracted every 24 hours of the test solution for a total of 7 days.

If the corrosion products precipitation is zero, the ions release rate $R_{r}$ for one period of time can be calculated according to equations 2 and 3 ,

$R_{r}=\frac{i}{t}$

$i=C V$

where $i=$ ions released $(\mu \mathrm{g}), C=$ ions release concentration $\mu \mathrm{g} / \mathrm{L}$, and $V=$ Volume of solution (L).

For $n$ periods of measurement, the ions release rate $\left(R_{r_{n}}\right)$ was evaluated according to equation 4

$R_{r_{n}}=\frac{C_{n} V_{n}}{\left(t_{n}-t_{n-1}\right)}$

where $R_{r_{n}}=$ ions release rate $\left(\mu \mathrm{gh}^{-1}\right)$ in the period $n, C_{n}=$ ions released concentration $\left(\mu \mathrm{gL}^{-1}\right)$ in the period $n, V_{n}=$ Volume of solution $(\mathrm{L})$ in the period $n$, and $t_{n}=$ immersion time (h) of period $n$.

Determination of ions release concentration of $\mathrm{Co}, \mathrm{Cr}$ and Mo was performed by means of inductively coupled plasma optical emission spectrometry (ICP-OES) using a Spectro $\AA^{\circledR}$ analytical instrument FMA-03 and by direct absorption of the test solution. Single element standard solutions of $\mathrm{Co}, \mathrm{Cr}, \mathrm{Mo}, \mathrm{Ti}, \mathrm{Al}, \mathrm{V}$ were prepared from their respective concentration standards $\left(0-10 \mathrm{mgL}^{-1}\right.$ for each element) to determine the slope of the calibration plots with a correlation coefficient $r=0.998$. The detection limit of the three alloying elements $\mathrm{Co}, \mathrm{Cr}$, Mo were $11 \mu \mathrm{L}^{-1}$ for $\mathrm{Co}$, $37.4 \mu \mathrm{L}^{-1}$ for $\mathrm{Cr}, 66.3 \mathrm{LL}^{-1}$ for Mo and for the coating elements $\mathrm{Ti}, \mathrm{Al}$ and $\mathrm{V}$ were 30.6 $\mu \mathrm{L}^{-1}, 44.2 \mu \mathrm{L}^{-1}$ and $33.1 \mu \mathrm{L}^{-1}$ respectively. 


\subsection{Corrosion resistance and tribocorrosion behavior}

Before the corrosion and tribocorrosion tests were conducted the samples were cleaned with acetone and isopropyl alcohol in an ultrasonic bath and then a $1 \mathrm{~cm}^{2}$ area was delimited by double-painting with enamel. The corrosion and tribocorrosion studies were carried out using a potentiostat Gamry reference 600 with SBF plus $\mathrm{BSA}\left(\mathrm{pH}=7.4\right.$ at $36.5 \pm 1.5^{\circ} \mathrm{C}$.) used as the electrolyte. The tests were performed using a three electrode cell. A saturated calomel electrode (SCE) was the reference electrode; a flat platinum wire was the counter electrode and the sample was the working electrode. Before the potentiodynamic polarization test (PD) started, measurements from open circuit potential were recorded for $60 \mathrm{~min}$. The PD curves were obtained by scanning the applied potential from $-1.0 \mathrm{~V}$ to $1.5 \mathrm{~V}$ vs SCE at a rate of $0.116 \mathrm{mVs}^{-1}$. The experiments were conducted in aerated solutions. The temperature of the electrolyte was controlled by a recirculating bath of water at 36.5 $\pm 1.5^{\circ} \mathrm{C}$. The sample was immersed in $50 \mathrm{ml} \mathrm{SBF}$ plus BSA solution with a $1 \mathrm{~cm}^{2}$ of exposed area. The corrosion resistance of the multilayer was evaluated using semilogarithmic potential-current curves obtained by potentiodynamic polarization. The corrosion current (icorr) was calculated by linear fit and Tafel extrapolation of the polarization curve.

The tribocorrosion behavior of the sample was evaluated by monitoring the open circuit potential (OCP) as a function of applied load in a reciprocating sliding test using a CETRUMT2 Tribometer. Each sample was immersed in $50 \mathrm{ml}$ of SBF plus BSA in the three electrode cell and the cell was carefully aligned to the ball holder in $x, y$ and $z$ axis. The test began with a one hour stabilization period in the fluid before the start of sliding period. The sliding was performed with load parameters of $1 \mathrm{~N}$ and $2 \mathrm{~N}, 1 \mathrm{~Hz}$ frequency and a $10 \mathrm{~mm}$ reciprocating stroke (sliding length) against an alumina ball of $10 \mathrm{~mm}$ diameter with a duration of 30 minutes while the COF is continuously recorded. For the substrate alone, the Hertzian maximum contact pressure, $\mathrm{p}_{0}$, for an applied load $\mathrm{W}$, has been calculated according to equation 5

$$
p_{0}=\left\{\frac{6 W E^{* 2}}{R^{2} \pi^{3}}\right\}^{\frac{1}{3}}
$$


where $\mathrm{W}$ is $1 \mathrm{~N}$ and $2 \mathrm{~N}$ for this work and $\mathrm{R}$ is radius of the alumina ball and the contact modulus $\mathrm{E}^{*}$ is calculated by equation 6

$\frac{1}{E^{*}}=\frac{1-v_{1}^{2}}{E_{1}}+\frac{1-v_{2}^{2}}{E_{2}}$

where $E_{1}$ is the substrate elastic modulus, the $E_{2}$ is the alumina ball elastic modulus, $v_{1}$ and $v_{2}$ are Poisson's ratio of substrate and ball respectively [19]. The contact pressure po resulted in $575 \mathrm{MPa}$ and $724 \mathrm{MPa}$ for $1 \mathrm{~N}$ and $2 \mathrm{~N}$ loads respectively. The experimental values of $\mathrm{p}_{0}$ reported for knees and hips range between 13-25 MPa [42] which are much lower than those used in this work. Therefore, the chosen loads represent severe test conditions in terms of contact pressure for materials used in the artificial knees and hip. The test ends with a stabilization period of one hour. In order to compare the results of the tribocorrosion test, the wear rate for coated and uncoated samples, was calculated by dividing the wear volume in $\mathrm{mm}^{3}$ (measured in the worn area by means of profilometer Dektak $150)$ by the product of Normal force applied ( $1 \mathrm{~N}$ or $2 \mathrm{~N})$, sliding velocity $(.02 \mathrm{~m} / \mathrm{s})$ (which depends on the stroke and the frequency of the reciprocating sliding $(1 \mathrm{~Hz})$ ) and the sliding time (1800s).

\section{RESULTS AND DISCUSSION}

\subsection{SEM and XRD}

The cross section image of the TiAIVCN/CN $\mathrm{x}$ multilayer coating employed throughout this work is shown in Figure 2. The figure reveals a multilayer structure of 1 TiAIV layer, $9 \mathrm{CN}_{\mathrm{x}}, 9$ TiAIVCN layers and a $\mathrm{CN}_{\mathrm{x}}$ final top layer. $\mathrm{CN}_{\mathrm{x}}$ interlayers are dense and uniform and TiAIVCN layers are dense with columnar growth. The $\mathrm{CN}_{\mathrm{x}}$ interlayer interrupt the columnar growth of the TiAIVCN layers and could provide barrier to the dislocation motion and reduce the permeability of the coating. Figure 3

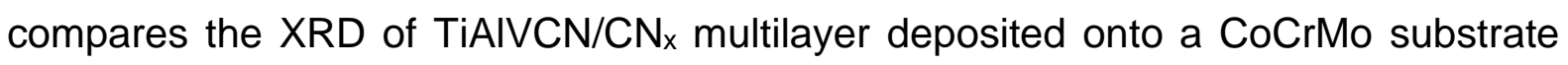
and a bare CoCrMo. Both diffraction plots match but the intensity of the coated CoCrMo peaks are attenuated due the presence of the multilayer coating. The XRD did not reveal the presence of extra peaks indicating that the multilayer has an 
amorphous structure, as it was expected for $\mathrm{CN}_{\mathrm{x}}$, because of the low substrate temperature used during the deposition process [16]. The diffractogram obtained also confirms the results of previous research which suggests that crystalline TIAICN/VCN multilayers and TiAICN coatings become amorphous when the carbon content increases [43]. In this case all layers have a carbon content equal or greater than $50 \%$ (see Figure 4 ).

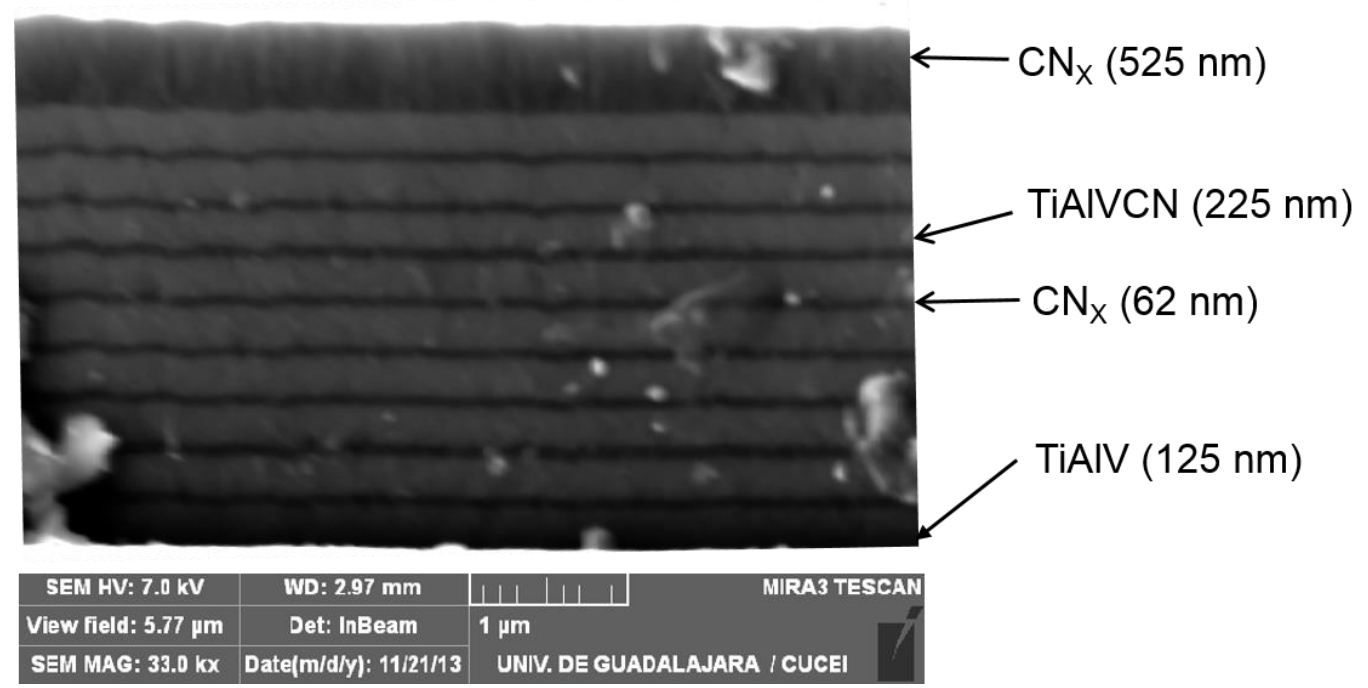

Figure 2. Cross sectional SEM image of multilayer TiAIVCN/CN at a working distance of $2.97 \mathrm{~mm}$. The figure shows 9 periods of TiAIVCN and $\mathrm{CN}_{\mathrm{x}}$ and the top $\mathrm{CN}_{\mathrm{x}}$ layer. 


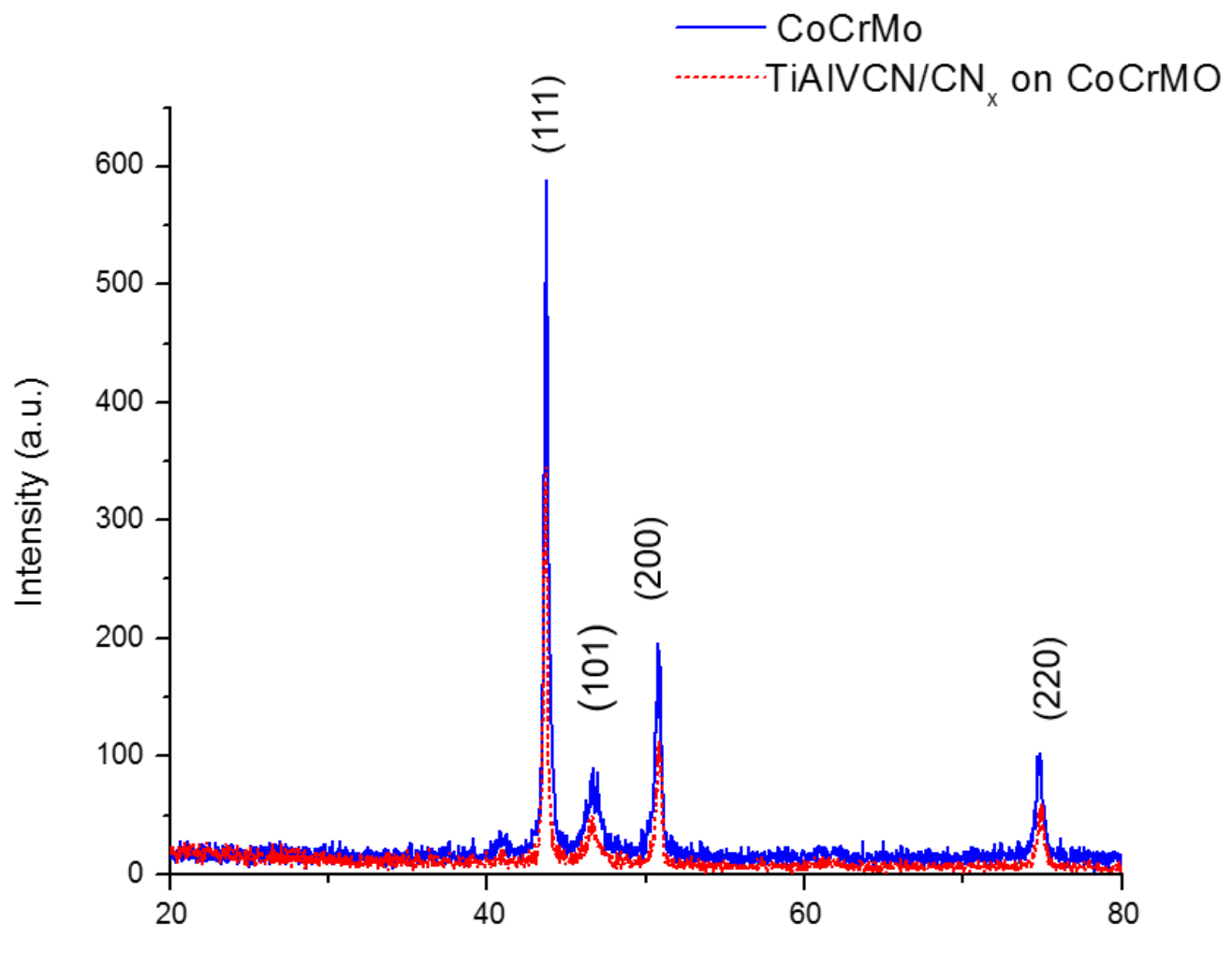

$2 \theta$

Figure 3. Comparison of diffractograms for the TiAIVCN/CNx multilayer deposited on a CoCrMo substrate and the uncoated substrate. The figure shows that the intensity of the coated CoCrMo peaks are attenuated due the presence of the amorphous multilayer coating.

\subsection{X-ray photoelectron spectroscopy (XPS)}

The elemental composition of the TiAIVCN/CN multilayer as a function of the sputter etch time and distance from the top layer is presented in Figure 4. In the $\mathrm{CN}_{\mathrm{x}}$ top layer, the $\mathrm{C}$ and $\mathrm{N}$ contents have values of $~ 85$ at\% and 14.2 at\%, respectively until a distance inside the multilayer of $\sim 500 \mathrm{~nm}$. The composition analyzed after 3000 s of sputter etching is congruent with the Figure 2 which shows a top layer of $\mathrm{CN}_{\mathrm{x}}$ with a thickness of $525 \mathrm{~nm}$. The TiAIVCN $\mathrm{N}_{\mathrm{x}}$ layer has a high $\mathrm{C}$ content ( 50 at\%), and a reduced $\mathrm{Al}$ content of $\sim 3.3$ at\% while the amounts of $\mathrm{N}$ and Ti resulted 30 at $\%$ and 14.2 at\%, respectively. Figure 5 shows the corresponding high resolution XPS core level recorded after 3000s, 3500s, 4000s, and 4500s of sputter etching. As expected, the intensity of the $\mathrm{C} 1 \mathrm{~s}$ core level spectra decreases considerably with increasing sputter etch time due to the lowered $C$ content in the TiAIVCN layer. $^{2}$ Apparent are the broad and very asymmetric $\mathrm{C} 1 \mathrm{~s}$ spectra recorded after 3500 s and 
4000s sputter etching. This is due to components arising at high binding energies (285.5 to $289.5 \mathrm{eV}$ ) ascribed to carbon bonded to nitrogen and oxygen [44]. In C1s core level spectra, acquired after 4500 s and at 5000s of sputter etching, these components shrink and components ascribed to carbon-metal bonds appear at lower energies, i.e. around $282.2 \mathrm{eV}$ and $283.2 \mathrm{eV}$ (in Figure 5 referred as to $\mathrm{C}-\mathrm{Me}$ ) $[45,46]$.

Due to the incorporation of $\mathrm{Ti}$ and $\mathrm{Al}$, an analogous shift in binding energies from mainly $\mathrm{N}-\mathrm{N}$ and $\mathrm{C}-\mathrm{N}$ bonds to nitrogen-metal bonds is observed in the low binding energy region of the N1s core level spectra, as shown in Figure 5. The most striking features are apparent in the $\mathrm{C} 1 \mathrm{~s}$ and N1s core level due to the incorporation of metals. The corresponding Al2p and Ti2p spectra are rather broad and the different components are not clearly identifiable. The core level spectrum of Al2p presumably comprises components of $\mathrm{Al}$ bonded to $\mathrm{O}$ and $\mathrm{N}$. The Ti2p contains most likely components where the metal is bonded to $\mathrm{N}, \mathrm{C}$ and $\mathrm{O}$. Any further conclusions as for the chemical bonding of $\mathrm{Al}$ and $\mathrm{Ti}$ are, thus, not possible.

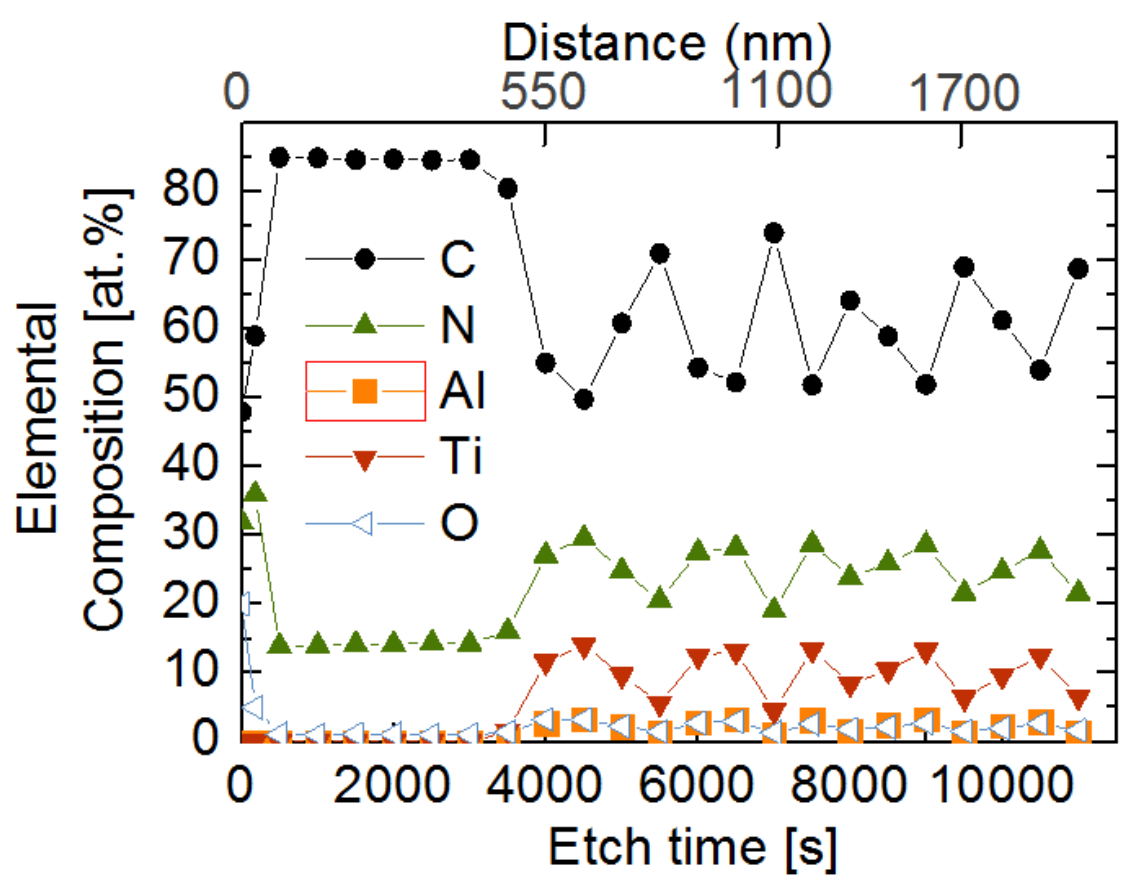

Figure 4. XPS elemental compositional profile in function of etch time (s) distance $(\mathrm{nm})$. Distance indicates the thickness of the TiAIVCN/CNx multilayer (from the surface of the top layer to inside the multilayer). 

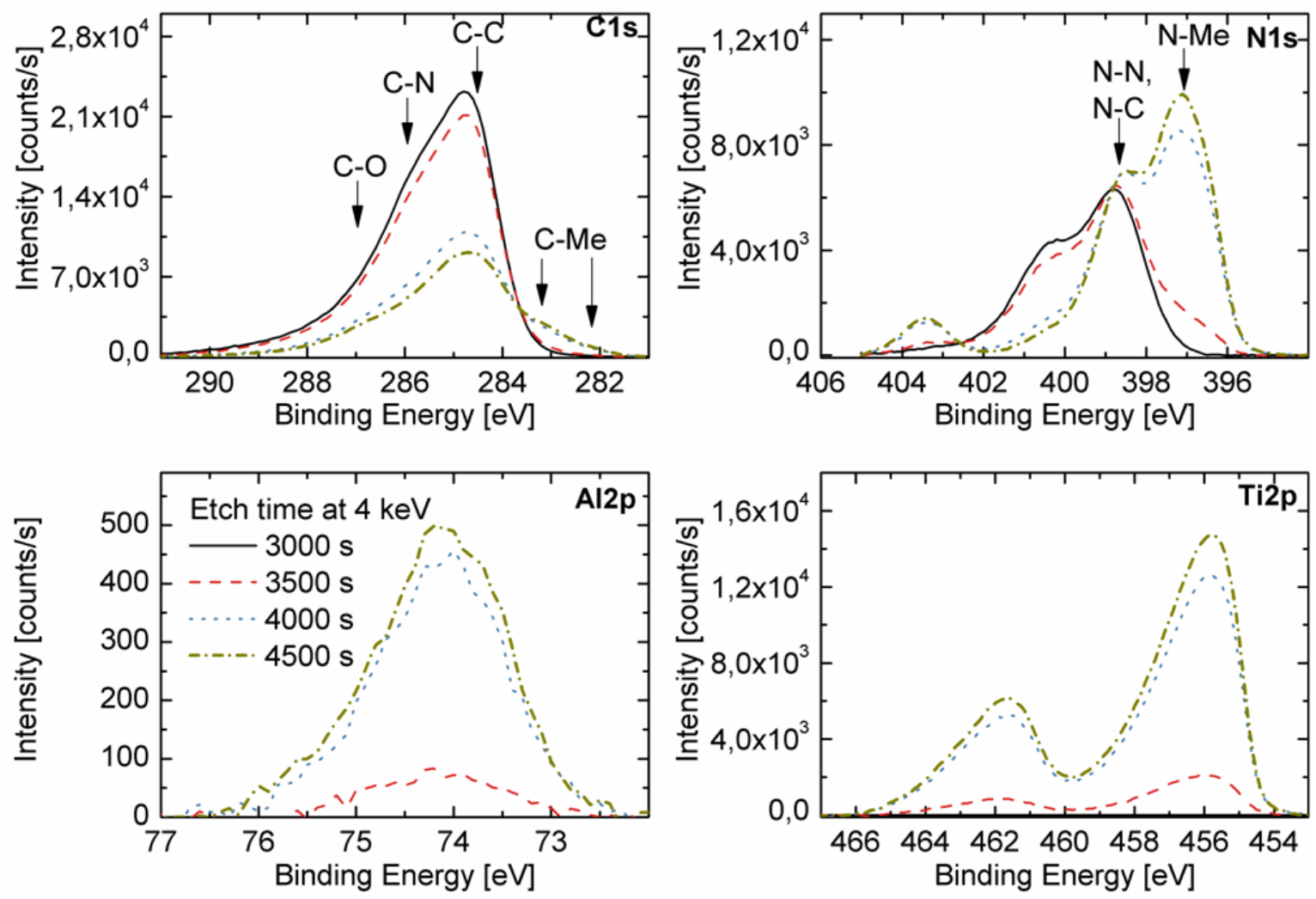

Figure 5. XPS binding energy of TiAIVCN/CN $\mathrm{N}_{\mathrm{x}}$ multilayer for $\mathrm{C} 1 \mathrm{~s}, \mathrm{~N} 1 \mathrm{~s}, \mathrm{Al} 2 \mathrm{p}$ and Ti2p.

\subsection{Nanoindentation}

Figure 6 shows the load displacement curves from nanoindentation measurements taken from the experiment described in section 2.3 for the TiAIVCN/CN $\mathrm{N}_{x}$ multilayer as compared to CoCrMo. Table 1 shows hardness $(\mathrm{H})$ and reduced elastic modulus $\left(\mathrm{E}_{\mathrm{r}}\right)$ calculated according to Oliver and Pharr approach [36]. The multilayer is slightly harder than the substrate but its $E_{r}$ is 2.5 times lower than the $E_{r}$ of the substrate. The percentage of elastic recovery (\%R) of the multilayer is almost 3 times higher than the elastic recovery of the substrate due the thick top layer of $\mathrm{CN}_{\mathrm{x}}$ as it has previously reported by Broitman et al. [16]. The $77 \%$ of elastic recovery suggest that the TiAIVCN/CN $\mathrm{N}_{\mathrm{x}}$ multilayer may have a higher wear resistance than the substrate [47]. From this result we conclude that our design of the multilayer deposited onto the CoCrMo alloy improves the mechanical properties of the substrate and will probably increase the material's lifetime. 


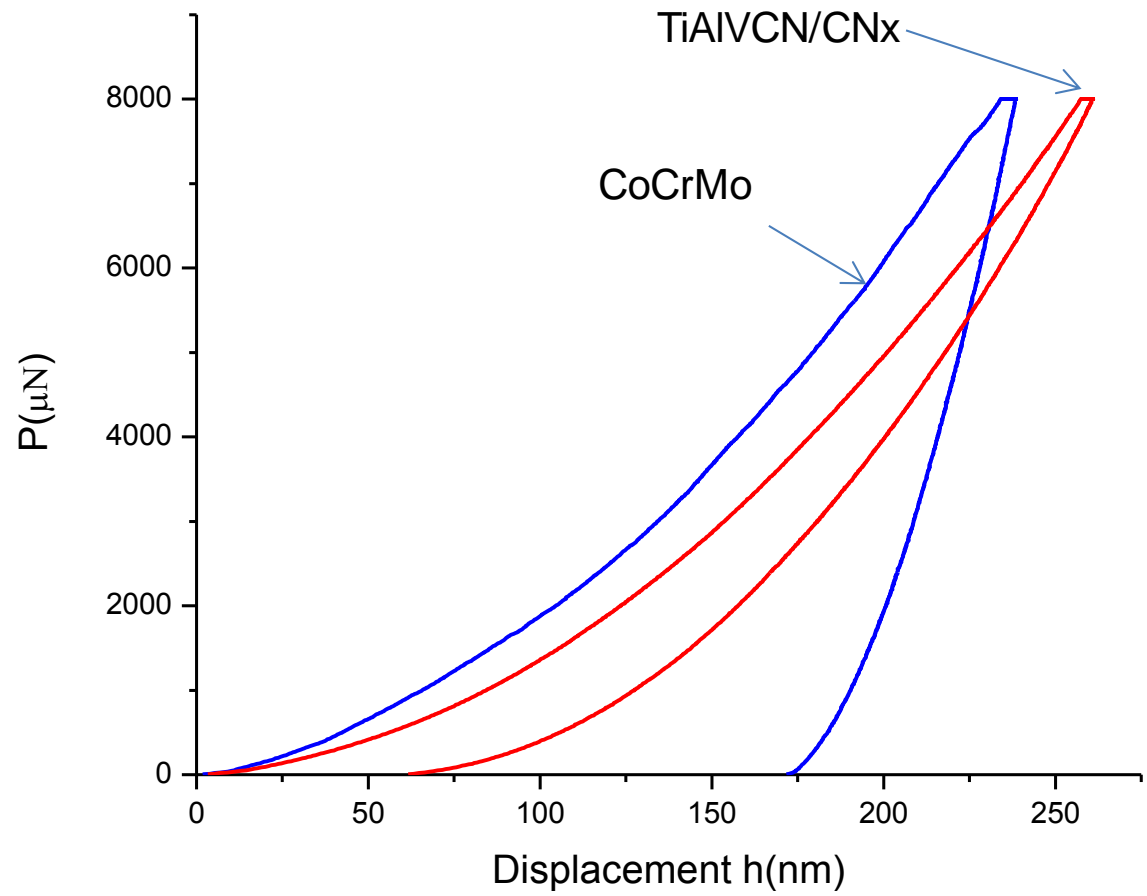

Figure 6.Nanoindentation loading and unloading curves of TiAIVCN/CN $\mathrm{N}_{\mathrm{x}}$ multilayer compared to CoCrMo substrate.

Table 1. Values of reduced elastic modulus (Er), Hardness $(\mathrm{H})$ and percentage of elastic recovery $(\% \mathrm{R})$ of uncoated CoCrMo substrate and coated with the TiAIVCN/CN multilayer.

\begin{tabular}{|lccc|}
\hline & $\mathrm{E}_{\mathrm{r}}(\mathrm{GPa})$ & $\mathrm{H}(\mathrm{GPa})$ & Elastic recovery $(\% \mathrm{R})$ \\
TiAlVCN/CN & & & \\
CoCrMo substilayer & $72 \pm 1$ & $9.4 \pm 0.19$ & $77 \pm 1.7$ \\
\hline
\end{tabular}

\section{4 lons released rate comparison results}

Table 2 shows the ion release concentration of cobalt (Co), chromium ( $\mathrm{Cr}$ ) and molybdenum (Mo) ions for the uncoated substrate obtained by immersion test in SBF plus BSA described in Section 2.4. The molybdenum ion release was significantly higher than the Co for the first measurement, within one hour of the experiment. 
Table 2. ICP results of ions release concentration and values of the calculated ions release rates $\left(R_{r_{n}}\right)$ of $\mathrm{Co}, \mathrm{Cr}$, Mo for the uncoated CoCrMo substrate immersed for $168 \mathrm{~h}$ in a Simulated Body Fluid (SBF) plus $4 \mathrm{gL}^{-1}$ of Bovine Serum Albumin (BSA), $\mathrm{pH} 7.4$, at $36.5 \pm 1.5^{\circ} \mathrm{C}$.

\begin{tabular}{|ccccc|cccc|}
\hline \multicolumn{4}{|c|}{ Ion release concentration } & & & \multicolumn{3}{c|}{$R_{r_{n}}=\frac{C_{n} V_{n}}{\left(t_{n}-t_{n-1}\right)}$} \\
\hline time & $\mathrm{V}_{\mathrm{n}}$ & $\mathrm{Co}$ & $\mathrm{Cr}$ & $\mathrm{Mo}$ & $\mathrm{t}_{\mathrm{n}}-\mathrm{t}_{\mathrm{n}-1}$ & $\mathrm{Co}$ & $\mathrm{Cr}$ & $\mathrm{Mo}$ \\
\hline $\mathrm{h})$ & $\mathrm{L}$ & $\mu \mathrm{g} \mathrm{L}^{-1}$ & $\mu \mathrm{g} \mathrm{L}^{-1}$ & $\mu \mathrm{g} \mathrm{L}^{-1}$ & $(\mathrm{~h})$ & $\mu \mathrm{g} \mathrm{h}^{-1}$ & $\mu \mathrm{g} \mathrm{h}^{-1}$ & $\mu \mathrm{g} \mathrm{h}^{-1}$ \\
\hline 1 & 0.2 & 0.0202 & 0.0746 & 0.0981 & 1 & 4.040 & 14.920 & 19.620 \\
3 & 0.19 & 0.0116 & 0.0772 & 0.0663 & 2 & 1.102 & 7.334 & 6.299 \\
6 & 0.18 & 0.0116 & 0.0733 & 0.0663 & 3 & 0.696 & 4.398 & 3.978 \\
24 & 0.17 & 0.0173 & 0.0679 & 0.138 & 18 & 0.163 & 0.641 & 1.303 \\
48 & 0.16 & 0.0116 & 0.0566 & 0.0976 & 24 & 0.077 & 0.377 & 0.651 \\
72 & 0.15 & 0.0116 & 0.0749 & 0.0752 & 24 & 0.073 & 0.468 & 0.470 \\
96 & 0.14 & 0.0116 & 0.0624 & 0.0663 & 24 & 0.068 & 0.364 & 0.387 \\
120 & 0.13 & 0.0266 & 0.0839 & 0.149 & 24 & 0.144 & 0.454 & 0.807 \\
144 & 0.12 & 0.0168 & 0.0602 & 0.1325 & 24 & 0.084 & 0.301 & 0.663 \\
168 & 0.11 & 0.0116 & 0.0653 & 0.1196 & 24 & 0.053 & 0.299 & 0.548 \\
\hline
\end{tabular}

a The results of the ions release concentration did not take in account the ions precipitation or reprecipitation on the surface of the CoCrMo and on the surface of the container therefore, this data were used only for to compare the ions release rate of uncoated CoCrMo versus the rate of CoCrMo coated with the TiAIVCN/CN $\mathrm{C}$ multilayer.

This significant difference trend continued throughout the rest of the experiment even when the $\mathrm{Co}$ and $\mathrm{Cr}$ ion release rates steadily decreased during the next 5 hours and finally stabilized. The differences in the ions release of $\mathrm{Co}, \mathrm{Cr}$ and $\mathrm{Mo}$ in comparison with other experiments in vitro $[12,48-50]$ in which the Co ion release is, in contrast, higher than the one for Mo and $\mathrm{Cr}$ could be ascribed either to the different media used in the immersion test, in this case SBF plus BSA or to the influence of the BSA content in the metal ions dissolution rate. About the BSA influence in the results obtained in the test, the adsorption of proteins can either decrease the corrosion and ion release rates, or enhance them depending on the adsorbed proteins and their interaction with the surface and the liquid medium [51]. These interactions are still not well understood in terms of binding with the metallic ions released [40]. But it is known that Bovine Serum albumin accelerates the ions metal precipitation and possess binding to a number of both bioorganic molecules and inorganic ions. BSA is able to bind transition metals as Co (II), Cu (II) and Ni (II) to its $\mathrm{NH}_{2}$ terminus, this ability is a useful chemical attribute with utility in clinical chemistry. These facts could explain the low $\mathrm{Co}^{+2}$ ions release concentration detected in the $10 \mathrm{ml}$ sample solution $[52,53]$. The media used in this experiment 
was similar to that used by Karimi et al., Phosphate Buffered Saline Solution (PBS) + $4 \mathrm{gL}^{-1}$ of Human Serum Albumin (HSA). The study showed that in presence of protein the dissolution rate of the Mo oxide increase to some extent and the ion release results showed that the Mo release was higher than $\mathrm{Cr}$ release after 8 immersion weeks, those results could be compared with the results obtained in this work although our samples were immersed in the solution just 1 week [49]. Lewis et al. obtained similar results analyzing the effect of synovial fluid on the dissolution and corrosion properties of CoCrMo in a 35- day immersion test. They observed that the $\mathrm{Cr}$ ions release concentration in the solution was the highest and the Co ions concentration the lowest and it was concluded that a protein film caused ligandinduced dissolution, increasing the Cr concentration in synovial fluid [54].

Despite the semiquantitative measurements of ion concentration, using the eq.4 it can be inferred that if the ions release rate was about constant after the first $24 \mathrm{~h}$, the surface of CoCrMo alloy became more passive and the ions precipitation rate were higher than the ion release rate.

In the case of multilayer coated samples, ICP results indicate that the $\mathrm{Co}, \mathrm{Cr}$, Mo, $\mathrm{Ti}, \mathrm{Al}$ and $\mathrm{V}$ ions release concentration levels were very low and the rate and quantification could not be obtained because their values were below the analytical detection limits of the test method. Therefore the ion release rate for $\mathrm{Co}, \mathrm{Cr}$ and $\mathrm{Mo}$ was not calculated. Nevertheless, these results confirm that the multilayer provided a significant barrier against the ions release in the physiological simulated fluid used in this work.

The original objective of this work was to compare the ions release of uncoated alloy versus the alloy coated with the TiAIVCN/CNx multilayer in presence of simulated physiological conditions and the aim was achieved. But the ions release results we obtained lead us to look for an explanation for the discussion of the high levels and low levels of Mo, Co and $\mathrm{Cr}$ ions released in SBF plus BSA in the long time immersion test. But a sustainable comparison with the results presented in "similar" experimental conditions by other groups was not possible to do. Therefore, we suggest that the measurement in vitro of trace metal concentration for metallic medical implants as CoCrMo alloy must present a standard set of methodological issues. In order to get an acceptable level of trace metals in long periods of time, a guideline of these issues need to be established to standardize the analytical 
methods (measurement of ion concentration), collection techniques and standard media solutions used.

\subsection{Corrosion}

The polarization curves of the uncoated and coated alloy in SBF plus BSA are shown in Figure 7. In order to understand better the electrochemical behavior of both uncoated and coated alloy in the studied solutions, four regions, indicated by dashed horizontal lines, can be observed in the Figure 7. In the first region the CoCrMo uncoated alloy exhibits a passive range characterized by a constant evolution of the value of current density due to the formation of layer highly enriched with $\mathrm{Cr}(90 \% \mathrm{Cr}$ oxides) on the alloy surface. The second region for the CoCrMo is known as the transpassive region determined by an abrupt increase of the current density, this behavior has been interpreted as the transpassive dissolution of $\mathrm{Cr}^{+3}$ to $\mathrm{Cr}^{+6}$ and water oxidation by other research groups $[11,55,56]$. According to Bettini et al., at the potential value of $0.7 \mathrm{~V}$ there is no severe corrosion of CoCrMo alloy in phosphate buffered saline (PBS) solution at room temperature around the point where the region 3 starts [57] but above this potential (region 3 ) in this work, the current starts to increase indicating the initiation of the corrosion process at breakdown potential of $+0.67 \mathrm{~V}$. SEM analysis of the CoCrMo uncoated surface shows that the surface was severely attacked and exhibits a high density of pits, see Figure 8a. Mathew et al. showed as well that surfaces of low carbon CoCrMo immersed in protein charged solution similar to that used in this research, exhibited a great quantity of pits due the pitting corrosion after the potentiodynamic test [58]. It also has been reported that the current recorded at the transpassive zone was not dominated by chromium dissolution but by other electrochemical reactions as water oxidation, the presence of pits and the influence of the BSA (protein) in the growth of the passive and protective film $[57,58]$. Therefore, at potentials higher than $\sim 0.56 \mathrm{~V}$, the localized corrosion on the CoCrMo substrate surface immersed in SBF+BSA, could have started in the grain boundaries or in some specific weak points of the passive layer [59]. A semi quantitative analysis by means of Energy-Dispersive X-ray spectroscopy (EDS) was made on the surface inside the pit (see Figure $8 \mathrm{~b}$ ), the results obtained in mass are: $(\mathrm{C}) 25.52 \%,(\mathrm{O}) 28.61 \%,(\mathrm{Mg}) 0.12 \%,(\mathrm{Na}) 1.70 \%$, (Si) $2.27 \%$, (P) 0.56\%, (Cl) 0.71, (K) 1.71\%, (Ca) 1.37\%, (Cr) 21.02\%, (Co) 10.27\%, Mo 5.50\%. This indicates that the concentration of the saline elements of solutions and corrosion 
products in the bottom of the pit could change the $\mathrm{PH}$ at this region converting the process to an autocatalytic one and promoting the growth of the pit. The layer of the corrosion products formed on the bottom of the pit has several cracks and therefore, did not protect the surface against the pitting.

For the case of samples coated with the multilayer, the following can be observed. The anodic part of the potentiodynamic curve of the TiAIVCN/CN $N_{x}$ multilayer exhibits a passive behavior without any change in the slope of the curve in the studied regions. In Table 3 , the value of the potential corrosion ( $\left.E_{c o r r}\right)$ of the uncoated CoCrMo alloy is more negative than the TiAIVCN/CN ${ }_{x}$, indicating that the coated sample has a lower tendency to be corroded. The icorr value, obtained by Tafel extrapolation, is higher for the uncoated sample than for the coated CoCrMo therefore, the corrosion rate was 2 times lower for the multilayer coated sample. For these reasons, we can conclude that the multilayer coating provides protection from pitting and general corrosion.

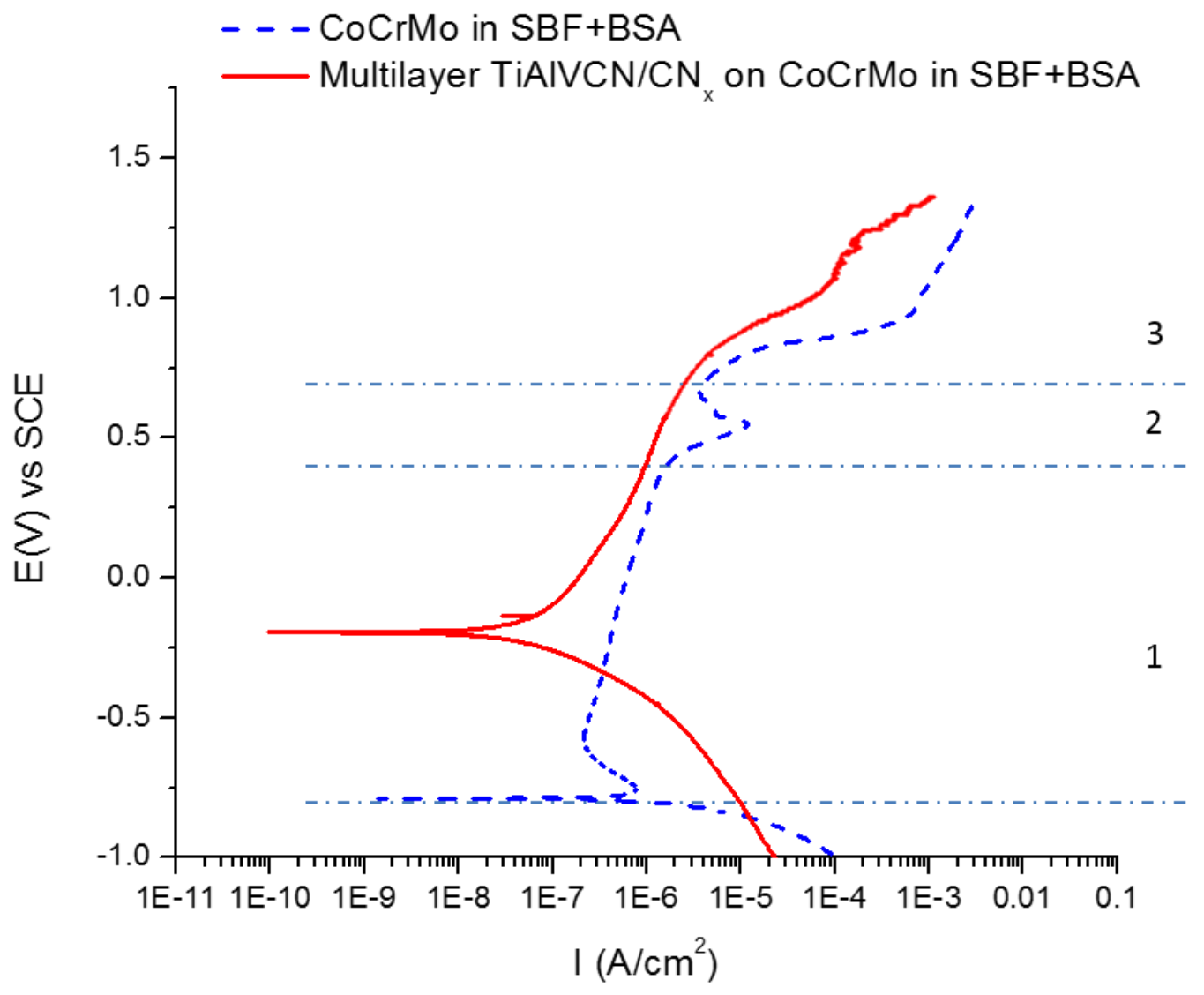

Figure 7. Potentiodynamic polarization curves for the multilayer coated and uncoated surfaces of $\mathrm{CoCrMo}$ in SBF+BSA at $36.5 \pm 1.5^{\circ} \mathrm{C}(\mathrm{pH} 7.4)$. The dashed horizontal lines indicate regions of interest described in Section 3.5. 
Table 3. Values of Ecorr, icorr of uncoated CoCrMo substrate and coated with TiAIVCN/CN multilayer.

\begin{tabular}{|lcc|}
\hline & $\mathrm{E}_{\text {corr }}(\mathrm{V})$ & $\mathrm{i}_{\text {corr }}\left(\mathrm{Acm}^{-2}\right)$ \\
TiAIVCN/CN $\mathrm{CN}_{\mathrm{x}}$ multilayer & $-0.19 \pm .09$ & $7.4 \times 10^{-8}$ \\
CoCrMo substrate & $-0.78 \pm .18$ & $1.32 \times 10^{-7}$ \\
\hline
\end{tabular}

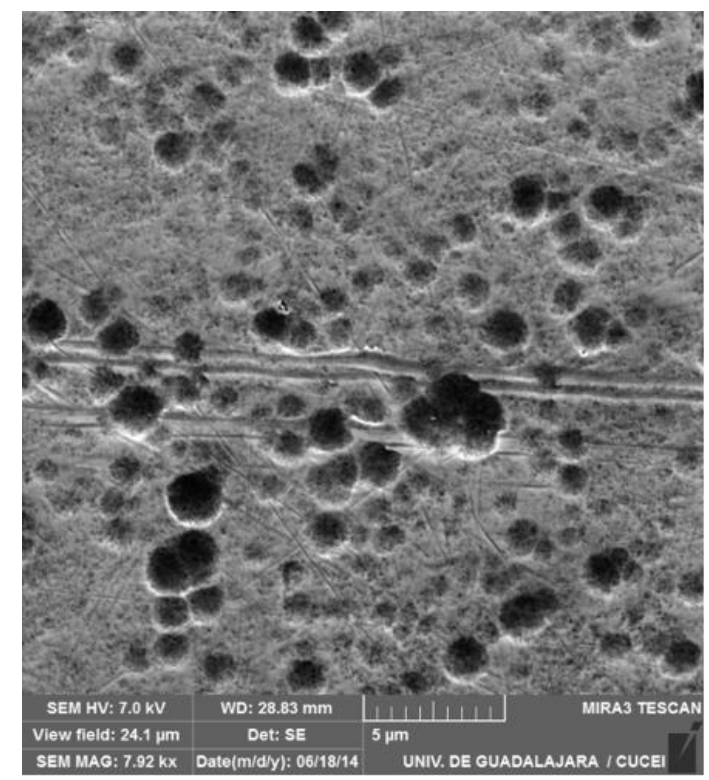

(a)

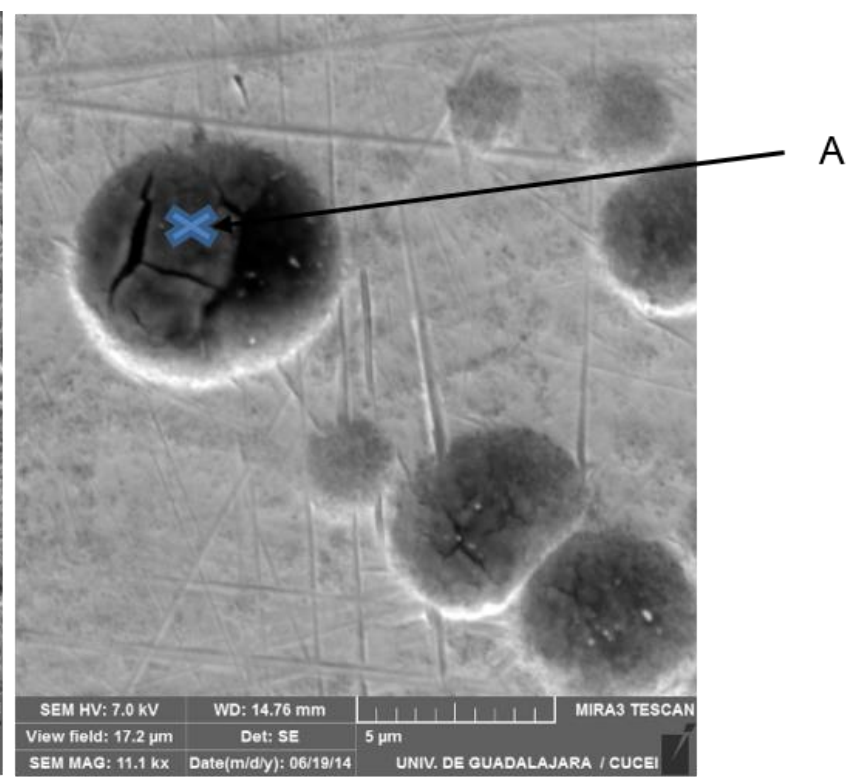

(b)

Figure 8.SEM images of corroded surface of LC CoCrMo alloy in SBF+BSA at $36.5 \pm 1.5^{\circ} \mathrm{C}(\mathrm{pH} 7.4)$ : (a) Severe attack of the alloy surface (b) The surface semiquantitative analysis of the pit area A selected is described in section 3.5.

\subsection{Tribocorrosion}

Figure 9 shows the comparison of the open circuit potential (OCP) measured before, during, and after the sliding phase for the coated and uncoated samples under $1 \mathrm{~N}$ and $2 \mathrm{~N}$ loads. For the uncoated substrate at the moment of immersion in the SBF plus BSA, the potential reaches $-110 \mathrm{mV}$ and the potential increases slightly to $-100 \mathrm{mV}$ during the first hour of the stabilization period, indicating a passivation of the surface. The potential of coated samples is more noble than the substrate and remained near to $-20(+-40 \mathrm{mV})$ during the first hour stabilization period indicating 
that the substrate surface coated with TiAIVCN/CN $\mathrm{C}_{\mathrm{x}}$ is more stable and has a lesser tendency to be corroded than the CoCrMo surface. During the period of reciprocating sliding for the CoCrMo under load, the potential decreased to the values of $-450 \pm 40 \mathrm{mV}$ and $-475 \pm 40 \mathrm{mV}$ for $1 \mathrm{~N}$ and $2 \mathrm{~N}$ respectively, the sliding leads to the formation of more chemically active regions in the friction zone and the potential in not stable during the $1800 \mathrm{~s}$ period of the sliding time indicating probably a local depassivation and repassivation process on the substrate surface. According to Mischler et al. the change in the potential indicates that under rubbing conditions the passive film on the sample surface was locally removed thus exposing bare metal to the solution and therefore the rubbed areas experienced an increase in metal oxidation rate because the loss of passivity [7]. Furthermore, an important surface degradation on the CoCrMo substrate is observed on the wear rate, as is shown in Figure 10. When the multilayer coatings were tested, the reciprocating sliding produced a very low change on the OCP when the loads of $1 \mathrm{~N}$ and $2 \mathrm{~N}$ were applied. The potential reached is $-80 \pm 15$ and $-100 \pm 20 \mathrm{mV}$ for $1 \mathrm{~N}$ and $2 \mathrm{~N}$ respectively. Those potential values are more positive than the potential of the substrate even before the sliding phase. During the sliding time some increase of the potential $E$ and the tendency to be more positive could be observed indicating that the multilayer coated surface has a tendency to the passivation. Figure 11a and 11b shows that the COF of the multilayer coating averages at $0.27 \pm 02$ and $0.18 \pm 0.01$ for $1 \mathrm{~N}$ and $2 \mathrm{~N}$ and remained stable during the sliding phase. The low friction coefficient and its stability of a similar multilayer coating were reported by Cheikh et al. [35]. These values are significantly lower than the COF of the uncoated sample which were $0.59 \pm 0.06$ for $1 \mathrm{~N}$ and $0.57 \pm 0.07$ for $2 \mathrm{~N}$ (see Figure 11c, 11d). Therefore very low degradation on the top layer of the coating was observed (see Figure 12). The wear rate calculated of the coated samples is about 6 times lower for $1 \mathrm{~N}$ and about 7 times lower for $2 \mathrm{~N}$ as is shown in Figure 10. The average contact pressure calculated of $1 \mathrm{~N}$ and $2 \mathrm{~N}$ is $575 \mathrm{MPa}$ and $724 \mathrm{MPa}$ respectively. Regarding to the OCP behavior after the sliding time under load and during the stabilization time, in both cases, coated and uncoated CoCrMo alloy, the potential rose up to a more noble value, to almost the same value that the OCP had before the sliding phase started.

A comparison of the OCP and COF monitored during the tribocorrosion test and the measurement of the decrease of wear rate have demonstrated the ability of the 
TiAIVCN/CN $\mathrm{N}_{\mathrm{x}}$ multilayer under $1 \mathrm{~N}$ and $2 \mathrm{~N}$ loads in SBF plus BSA fluid to protect the substrate against the tribocorrosion.

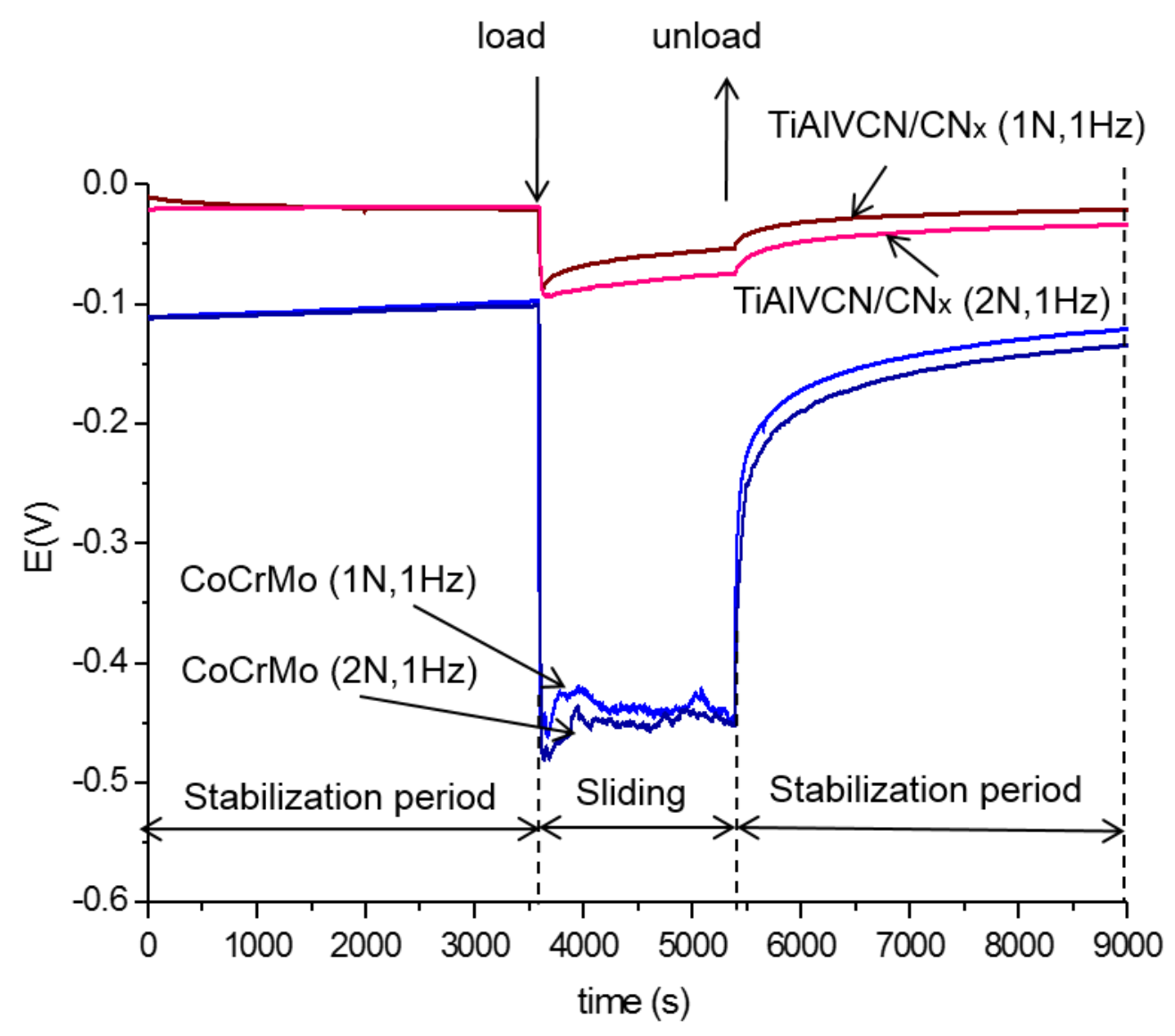

Figure 9.Comparison OCP monitoring of the tribocorrosion test for the multilayer and substrate CoCrMo, under $1 \mathrm{~N}$ and $2 \mathrm{~N}$ loads, $1 \mathrm{~Hz}$, in SBF plus BSA fluid at $36.5 \pm$ $1.5^{\circ} \mathrm{C}$. 


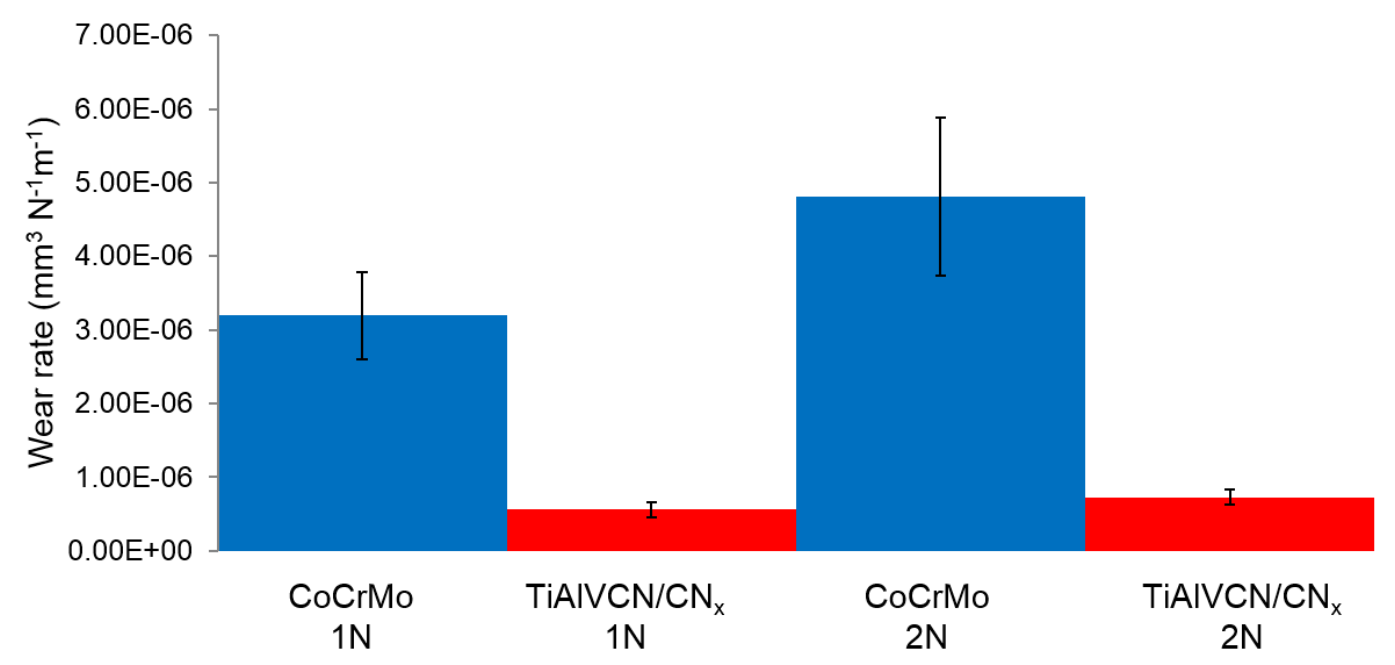

Figure 10. Wear rate comparison of the multilayer coating TiAIVCN/CN $N_{x}$ and the substrate CoCrMo under $1 \mathrm{~N}$ and $2 \mathrm{~N}$ at $.02 \mathrm{~m} / \mathrm{s}(1 \mathrm{~Hz})$ during $1800 \mathrm{~s}$ in SBF+BSA fluid at $36.5 \pm 1.5^{\circ} \mathrm{C}$.

(a)

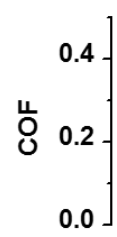

TiAIVNCN/CN on CoCrMo $1 \mathrm{~N}$
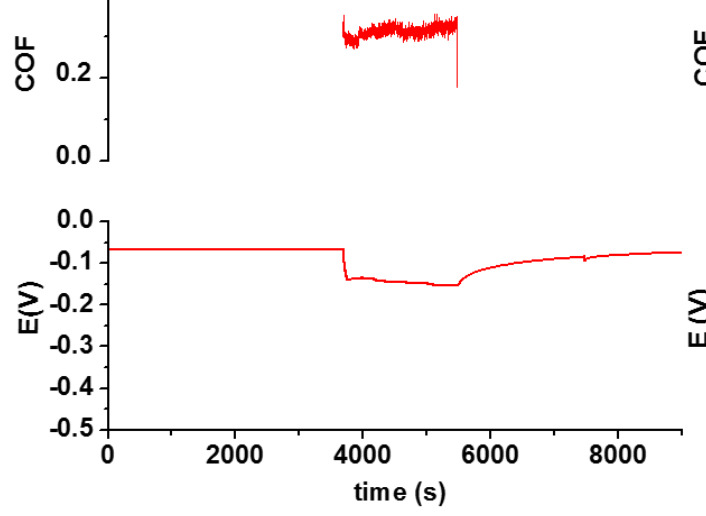

CoCrMo uncoated alloy $1 \mathrm{~N}$

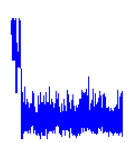

(c)
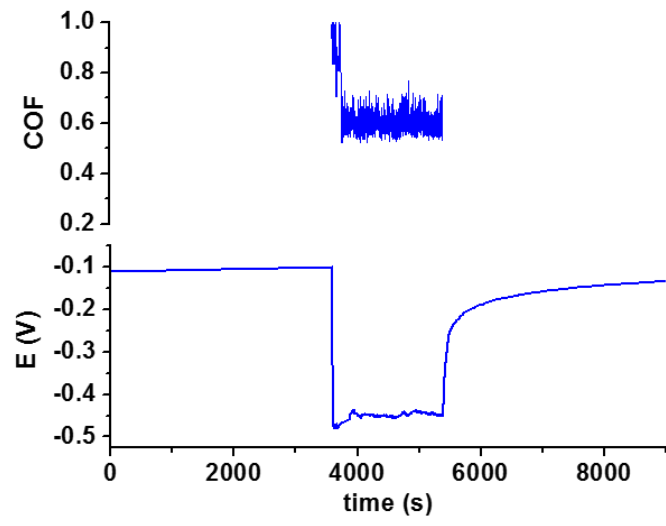

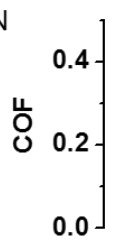

TiAIVCN/CN $\mathrm{N}_{\mathrm{x}}$ multilayer on CoCrMo $2 \mathrm{~N}$

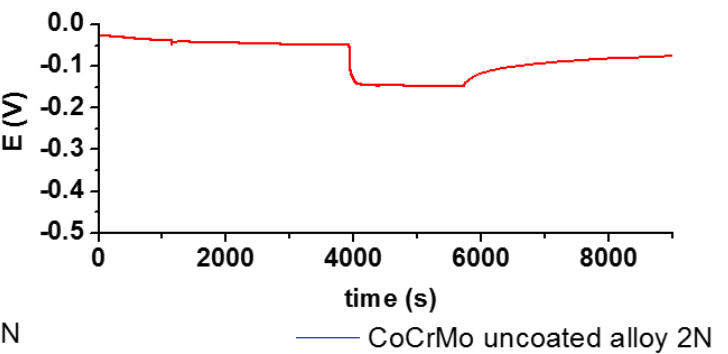

(b)

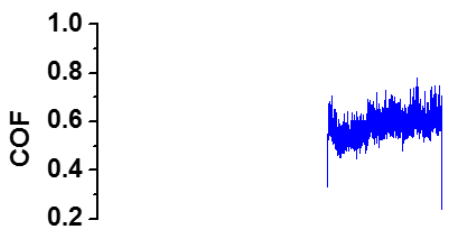

(d)

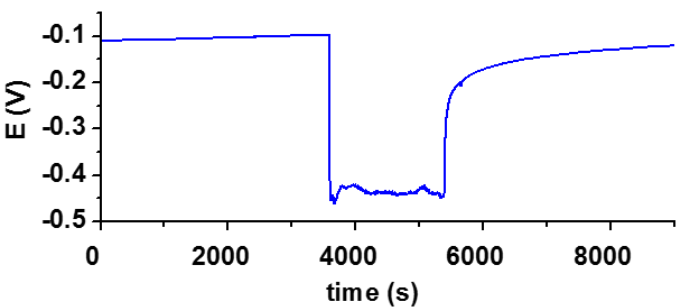

Figure 11. Friction coefficient (COF) and overlaid with the Open Circuit potential (OCP) monitoring graph for: a) The multilayer on CoCrMo under $1 \mathrm{~N}$ b) The multilayer on CoCrMo under $2 \mathrm{~N} \mathrm{c}$ ) The CoCrMo alloy under $1 \mathrm{~N}$ d) The CoCrMo alloy under $2 \mathrm{~N}$ of load during the sliding phase, submerging in SBF+BSA fluid at $36.5 \pm 1.5^{\circ} \mathrm{C}$ in tribocorrosion test . 


\section{CONCLUSIONS}

A novel multilayer coating consisting of alternating TiAIVCN and a-CN $\mathrm{CN}_{x}$ layers with a thick top a- $\mathrm{CN}_{\mathrm{x}}$ layer was deposited on $\mathrm{CoCrMo}$ biomedical alloy samples using magnetron sputtering. XPS results indicate that the top $\mathrm{CN}_{x}$ layer has $\mathrm{C} \sim 85$ at $\%$ and the TiAIVCN layer 50 at\% $\mathrm{C}$ and reduced Al content. The XPS spectra show high binding energy for $\mathrm{C}-\mathrm{N}$ but low binding energy for TiAIV-C i.e. metal carbon. No crystalline phase was observed by XRD analysis; these results indicated that, for this carbon content (50 at\% to 85 at\%) the TiAICN/CN $/ N_{x}$ multilayer is amorphous. Nanoindentation experiments show that the TiAIVCN/CN $\mathrm{N}_{x}$ multilayer coating improved the mechanical properties over the uncoated substrate; higher hardness and higher elastic recovery percentage are recorded. Potentiodynamic polarization tests indicate that the multilayer enhances the corrosion resistance of the substrate in simulated body fluid plus bovine serum albumin. The multilayer coating provided reduced coefficient friction to the substrate during the sliding phase of the tribocorrosion test, this behavior can be attributed to the carbon-based amorphous top layer $\left(\mathrm{a}-\mathrm{CN}_{\mathrm{x}}\right)$. Very low degradation on the top layer of the coating was observed and it was quantified with the wear-rate. The wear-rate calculated for the multilayer coating was about 6 to 7 times lower than for the uncoated substrate. The lower tendency of the coated samples to be corroded under applied loads (as shown by the OCP evolution) and the protection that the multilayer provides to the substrate against pitting corrosion could be important factors that influence the tribocorrosion behavior of these materials. ICP comparison results demonstrate that the multilayer coating effectively blocked the emigration of metallic ions. Thus, we conclude that the amorphous TiAIVCN/CN $\mathrm{N}_{\mathrm{x}}$ multilayer, which combines properties of the individual layer materials TiAIVCN and a- $\mathrm{CN}_{x}$ offers a multifunctional protection alternative to the substrate, providing to the CoCrMo biomedical alloy improved mechanical properties and increased protection against pitting corrosion and tribocorrosion in protein charged body fluids. 


\section{Acknowledgements}

The authors acknowledge the financial support received from CONACYT, FOMIX Jal-2010-10-149472. EB acknowledges the Swedish Government Strategic

Research Area in Materials Science on Functional Materials at Linköping University (Faculty Grant SFO-Mat-LiU \# 2009-00971). JH and BA acknowledges support from the Tecnológico de Monterrey research seed fund.

The authors acknowledge Dr. Susann Schmidt and Dr. Lars-Åke Näaslund from Linköping University (Sweden) for the XPS characterization and further discussions and to Lizette Reyes, Luis Manuel Aparicio from Tecnológico de Monterrey and Luis Alberto Lopez from Universidad de Guadalajara for the ions release test and ICP measurements.

\section{References}

[1] Jozef A. Helsen and Yannis Missirls. Biomaterials Ch. Intoxicated by Implants. Biological and Medical Physics, Biomedical Engineering. Springer Berlin Heideberg; 2010. doi:10.1007/978-3-642-12532-4_4

[2] A.J. Hart, P. D. Quinn, B. Sampson, A. Sandson, K. D. Atkinson, J. A. Skinner, et al. The chemical form of metallic debris in tissues surrounding metal-on-metal hips with unexplained failure. Acta Biomater 2010; 6 (11):4439-4446.

[3] A. Sargeant, T. Goswami. Hip implants-paper VI-ion concentrations. Mater Des 2007; 28 (1): 155-171.

[4] Services, U.S.D.o.H.H. Recalls Specific to Metal-on-Metal Hip Implants. 2010. Last accessed March 16, 2014. Available from:

http://www.fda.gov/MedicalDevices/ProductsandMedicalProcedures/ImplantsandPro sthetics/MetalonMetalHip/mplants/ucm241770.htm.

[5] J. Hesketh, Q. Meng, D. Dowson, A. Neville. Biotribocorrosion of metal-on-metal hip replacements: How surface degradation can influence metal ion formation. Tribo Int 2013; 65:128-137.

[6] S. Mischler, E.A. Rosset, D. Landolt. Effect of Corrosion on the Wear Behavior of Passivating Metals in Aqueous Solutions. Tribology Series 1993; 25: 245-253.

[7] S. Mischler, A.I. Muñoz. Wear of CoCrMo alloys used in metal-on-metal hip joints: A tribocorrosion appraisal. Wear 2013; 297 (1-2):1081-1094.

[8] M. T. Mathew, P. Srinivasa Pai, R. Pourzal, A. Fischer, M. A. Wimmer, Significance of Tribocorrosion in Biomedical Applications: Overview and Current Status. Advances in Tribology 2009, 12. 
[9] S.Virtanen, I. Milosev, E. Gomez-Barrena, R.Trebse, J. Saly, V.T. Kontinnen. Special modes of corrosion under physiological and simulated physiological conditions. Acta Biomater 2008; 4(3): 468-476.

[10] C. Valero Vidal, A. Olmo Juan, A. I. Muñoz. Adsorption of Bovine Serum Albumin on CoCrMo Surface: Effect of temperature and protein concentration. Colloids and Surface B: Biointerfaces 2010; 80: 1-11.

[11] C. Valero Vidal, A. I. Muñoz. Electrochemical characterisation of biomedical alloys for surgical implants in simulated body fluids. Corros Sci 2008; 50: 1954-1961.

[12] T. Hanawa. Metal ion release from metal implants. Mater Sci Eng 2004; C24: 745-752.

[13] Dearnaley, G. and J.H. Arps. Biomedical applications of diamond-like carbon (DLC) coatings: A review. Surf Coat Technol 2005; 200(7): 2518-2524.

[14] G. Thowarth, C.V. Falub, U. Müller, B. Weisse, C. Voisard, M. Tobler, et al. Tribolological behavior of DLC-coated articulating joint implants. Acta Biomater 2010; 6: 2335-2341.

[15] C.A. Charitidis. Nanomechanical and nanotribological properties of carbon based thin films. A review. Int J Refract Met Hard Mater 2010; 28: 51-70

[16] E. Broitman, N. Hellgren, O. Wanstrand, M.P. Johanson, T.Berlind, H. Sjöström, et al. Mechanical and tribological properties of $\mathrm{CN}_{\mathrm{x}}$ films deposited by reactive magnetron sputtering. Wear 2001; 248 (1-2): 55-64.

[17] E. Broitman, Zs. Czigány, G. Greczynski, J. Böhlmark, R. Cremer, L. Hultman. A Industrial-scale deposition of highly adherent $\mathrm{CN}_{x}$ films on steel substrates. Surf Coat Technol 2010; 204: 3349-3357.

[18] E. Broitman, and L. Hultman. Adhesion Improvement of Carbon-based Coatings through a High Ionization Deposition Technique. J Phys Conf Ser 2012; 370: 012009.

[19] E. Broitman, W. Macdonald, N. Hellgren, G. Radnóczi, Zs. Czigány, A. Wennerberg, et al. Carbon nitride films on orthopedic substrates. Diam Relat Mater 2000; 9: 1984-1991.

[20] D.G. Liu, J.P. Tu, R. Chen, C.D. Gu. Microstructure, corrosion resistance and biocompatibility of titanium incorporated amorphous carbon nitride films. Surf Coat Technol 2011; 206: 165-171.

[21] V.K. William Grips, H. C Barshilia, V. E. Selvi, Kalavati, K.S. Rajam.

Electrochemical behavior of single layer $\mathrm{CrN}$, TiN, TiAIN coatings and nanolayered TiAIN/CrN multilayer coatings prepared by reactive direct current magnetron sputtering. Thin Solid films 2006; 514(1-2): 204-211.

[22] J.K. Wood. Tribo-corrosion of coatings: a review. J. Phys. D: Appl Phys 2007; 40(18): 5502-5521. 
[23] M. Braic, M. Balaceanu, V. Braic, A. Vladescu, T. G. Pavelescu, M. Albulescu. Synthesis and characterization of TiN, TiAIN and TiN/TiAIN biocompatible coatings. Surf Coat Technol 2005; 200: 1014-1017

[24] C. Balagna, M.G. Faga, and S. Spriano. Tantalum-based multilayer coating on cobalt alloys in total hip and knee replacement. Mater Sci Eng: C 2012; 32 (4): 887895.

[25] J.R. Goldberg, J.L. Gilbert. The electrochemical and mechanical behavior of passivated and TiN/AIN-coated CoCrMo and Ti6Al4V alloys. Biomaterials 2004; 25(5): 851-864.

[26] Leigh Booth, Shane A. Catledge, Dustin Nolen, Raymond G Thompson, Yogesh K. Vohar. Synthesis and Characterization of Multilayered Diamond Coating for Biomedical Implants. Materials 2011; 4: 857-868.

[27] G.S. Was, T. Foecke. Deformation and fracture in micro laminates. Thin Solid Films. 1996; 286: 1-31.

[28] S.J. Bull, A.M. Jones. Multilayer coatings for improved performance. Surf Coat Technol 1996; 78: 173-184.

[29] K. Zhang, M. Wen, Q.N. Meng, Y. Zeng, C.Q. Hu, C. Liu, W.T. Zheng. Structure, mechanical property, and tribological behavior of c-NbN/CN $\mathrm{x}$ multilayers grown by magnetron sputtering. Surf Coat Technol 2012; 206: 4040-4045

[30] B. Alemón, M. Flores, C. Canto, E. Andrade, E.Broitman. Ion beam analysis, corrosion resistance and nanomechanical properties of TiAICN/CN $<\mathrm{i}>\mathrm{x}<\mathrm{i}>$ multilayer grown by reactive magnetron sputtering. Nucl Instrum Methods Phys Res, Sect B 2014; 331: 134-139.

[31] O. Asturizaga, R. Sanjines, G. Margaritondo, F. Lévy. (TiAIV) $\mathrm{N}_{1-x}$ thin films deposited by reactive sputtering chemical composition. Surf Coat Technol 1993; 61: 30-35.

[32] Y. Yan, A. Neville, D. Dowson. Tribo-corrosion of cobalt-based medical implant alloys in simulated biological environments. Wear 2007; 263: 1105-1111.

[33] M.T. Mathew, M.J. Runa, M. Laurent, J.J. Jacobs, L.A. Rocha, M.A. Wimmer. Tribocorrosion behavior of CoCrMo alloy for hip prosthesis as a function of loads. A comparison between two testing systems. Wear 2011; 271: 1210-1219

[34] R. Bayón, R. Nevshupa, C. Zubizarreta, U. Ruiz de Gopegui, J. Barriga, A. Igartua. Characterisation of tribocorrosion behaviour of multilayer PVD coatings. Anal Bioanal Chem 2010; 396(8): 2855-2862

[35] B. Cheikh Larbi, B. Tlili. Fretting wear of multilayered PVD TiAICN/TiAIN/TiAI on AISI 4140 steel. Surf Coat Technol 2006; 201(3): 1511-1518.

[36] Luo Quanshun, Shun Cai Wang, Zhaoxia Zhou, Linghao Chen. Structure characterization and tribological study of magnetron sputtered nanocomposite ncTiAIV (N, C)/aC coatings. J Mater Chem 2011; 21(26): 9746-9756. 
[37] M. Flores, S. Muhl, E. Andrade. The relation between the plasma characteristic and the corrosion properties of TiN/Ti multilayers deposited by unbalanced magnetron sputtering. Thin Solid Films, 2003; 433(1): 217-223.

[38] W.C. Oliver, G.M. Pharr. An improved technique for determining hardness and elastic modulus using load and displacement sensing indentation experiments. $J$ Maters R 1992; 7(06): 564-1583.

[39] T. Kokubo, H. Takadama. How useful is SBF in predicting in vivo bone bioactivity? Biomaterials 2006; 27(15): 2907-2915.

[40] W. Bal, M. Sokolowska, E. Kurowska, P. Faller. Binding of transition metal ions to albumin: Sites, affinities and rates. Biochim Biophys Acta 2013; 1830: 5444-5455.

[41] Buddy D. Ratner, Allan S. Hoffman, Frederick J. Schoen, Jack E. Lemons. Biomaterials Science: An Introduction to Materials in Medicine. Appendix A. Academic Press, 2012.

[42] J.A. Szivek, P.L. Anderson, J.B. Benjamin. Average and peak contact stress distribution evaluation of total knee arthroplasties. J Arthroplasty 1996; 11(8): 952963.

[43] PE Hovsepian, G. Kamath, AP. Ehiasarian, R. Haasch, I. Petrov. Microstructure, Oxidation and Tribological Properties of TiAICN/VCN Coatings Deposited by Reactive HIPIMS. IOP Conference Series: Mater Sci Eng 2012; 39.

[44] S. E. Rodil, S. Muhl. Bonding in amorphous carbon nitride. Diam Relat Mater 2004; 13: 1521-1531.

[45] C.D. Wagner, G.E.M., Handbook of X-ray photoelectron spectroscopy: a reference book of standard data for use in X-ray photoelectron spectroscopy. Physical Electronics Division, Perkin-Elmer Corp1979.

[46] NIST X-ray Photoelectron Spectroscopy Database, Version 3.5 2003; Available from: http://srdata.nist.gov/xps/.

[47] H.Q. Lou, N. Axén, R.E. Somekh, I.M. Hutchings. Mechanical properties of amorphous carbon nitride films. Diam Relat Maters 1996; 5: 1303-1307.

[48] Mirjana Metikos-Hukovic, Zora Pilic, Ranko Babic, Dario Omanovic. Influence of alloying elements on the corrosion stability of CoCrMo implant alloy in Hank's solution. Acta Biomater 2006; 2: 693-700.

[49] Shima Karimi, Akram M. Alfantazi. Ion release and surface oxide composition of $316 \mathrm{~L}$, Co-28Cr-6Mo and Ti-6Al-4V alloys immersed in human serum albumin solutions. Mater Sci Eng C 2014; 40: 435-44.

[50] Ugur Turkan, Orhan Öztürk, Ahmet E. Eroglu. Metal ion release from TiN coated CoCrMo orthopedic implant material. Surf Coat Technol 2006; 200: 5020-5027.

[51] P. Silva, S.E. Rodil. An overview of proteins adsorption on metal oxide coatings for biomedical implants. Surf Coat Technol 2013; 233: 147-158. 
[52] R.H. Christenson, S.H. Duh, W.R. Sanhai, A.H. Wu, V. Holtman, P. Painter, et al. Characteristics of an Albumin Cobalt Binding Test for Assessment of Acute Coronary Syndrome Patients: A multicenter Study. Clinical Chemistry 2001; 47(3): 464-470.

[53] Hong Liang, Jin Huang, Chu-Qiao Tu, Min Zhang, Yong-Qia Zhou, Pan-Wen Shen. The subsequent effect of interaction between $\mathrm{Co}^{+2}$ and human serum albumin or bovine serum albumin. J Inorg Biochem 2001; 85: 167-171.

[54] A.C. Lewis, M.R. Kilburn, I. Papageorgiou, G.C. Allen, C.P. Case. Effect of synovial fluid, phosphate-buffered saline solution, and water on the dissolution and corrosion properties of CoCrMo alloys as used in orthopedic implants. J Biomed Mater Res part A 2005; 73A (4): 456-467.

[55] A.W.E. Hodgson, S. Kurz, S. Virtanen, V. Fervel, C.-O.A. Olsson, S. Mischler. Passive and transpassive behaviour of CoCrMo in simulated biological solutions. Electrochim Acta 2004; 49: 2167-2178.

[56] L. Casabán Julián, A. I. Muñoz. Influence of microstructure of HC CoCrMo biomedical alloys on the corrosion and wear behavior in simulated body fluids. Tribol Int 2011; 44: 318-329.

[57] E. Bettini, C. Leygraf, J. Pan. Nature of Current Increase for a CoCrMo Alloy: "transpassive" Dissolution vs. Water Oxidation. Int J Electrochem Sci 2013; 8: $11791-11804$.

[58] M.T. Mathew, C. Nageli, R. Pourzal, A. Fisher, M.P. Laurent, J.J. Jacobs. Tribolayer formation in a metal-on-metal (MoM) hip joint: An electrochemical investigation. J. Mech Behav Biomed Mater, 2014; 29: 199-212.

[59] Panigrahi, P., Liao, Y., Mathew, M. T., Fischer, A., Wimmer, M. A., Jacobs, J. J. Intergranular pitting corrosion of CoCrMo biomedical implant alloy. J Biomed Mater Res Part B: Applied Biomaterials 2014;102(4), 850-859. 